\title{
Glial dystrophin-associated proteins, laminin and agrin, are downregulated in the brain of $\mathrm{mdx}$ mouse
}

\author{
Beatrice Nico ${ }^{1, *}$, Roberto Tamma ${ }^{1, *}$, Tiziana Annese ${ }^{1}$, Domenica Mangieri ${ }^{2}$, Annamaria De Luca ${ }^{3}$, Patrizia Corsi ${ }^{4}$, \\ Vincenzo Benagiano ${ }^{1}$, Vito Longo ${ }^{5}$, Enrico Crivellato ${ }^{6}$, Andrea Salmaggi ${ }^{7}$ and Domenico Ribatti $^{1}$
}

In this study, we investigated the involvement of dystrophin-associated proteins (DAPs) and their relationship with the perivascular basement membrane in the brains of $m d x$ mice and controls at the age of 2 months. We analyzed (1) the expression of glial DAPs $\alpha$ - $\beta$-dystroglycan (DG), $\alpha$-syntrophin, aquaporin-4 (AQP4) water channel, Kir 4.1 and dystrophin isoform (Dp71) by immunocytochemistry, laser confocal microscopy, immunogold electron microscopy, immunoblotting and RT-PCR; (2) the ultrastructure of the basement membrane and expression of laminin and agrin; and (3) the dual immunofluorescence colocalization of $\mathrm{AQP} 4 / \alpha-\beta-\mathrm{DG}$, and of Kir 4.1/agrin. The following results were observed in $\mathrm{mdx}$ brain as compared with controls: (1) a significant reduction in protein content and mRNA expression of DAPs; (2) ultrastructurally, a thickened and discontinuous appearance of the basement membrane and a significant reduction in laminin and agrin; and (3) a molecular rearrangment of $\alpha-\beta$-DG, coupled with a parallel loss of agrin and Kir 4.1 on basement membrane and glial endfeet. These data indicate that in $m d x$ brain the deficiency in dystrophin and dystrophin isoform (Dp71) is coupled with a reduction of DAP components, coupled with an altered anchoring to the basement membrane.

Laboratory Investigation (2010) 90, 1645-1660; doi:10.1038/labinvest.2010.149; published online 16 August 2010

KEYWORDS: astrocyte; basement membrane; blood-brain barrier; DAPs; dystrophy

The blood-brain barrier (BBB) controls the selective exchanges between blood and neuropil by specific molecular and structural features of its vascular and perivascular components, including endothelial cells, pericytes, glial endfeet and basement membrane. ${ }^{1-3}$ Glial cells have a key role in the control of BBB development and integrity. They express in a polarized way, on their perivascular endfeet, carrier membranes and channel proteins, including aquaporin-4 (AQP4) water channel and potassium channel Kir 4.1, which are responsible for the water flow rate and spatial $\mathrm{K}^{+}$buffering control. ${ }^{4-9}$ In the retina, AQP4 colocalizes with Kir 4.1, ${ }^{9-11}$ suggesting a tight cooperation between the water flux and $\mathrm{K}^{+}$siphoning generated by neuronal activity at the BBB interfaces. Moreover, AQP4 and Kir 4.1 rearrangement has been described in BBB alterations, coupled with cytotoxic edema and $\mathrm{K}^{+}$-delayed buffering capacity. ${ }^{12,13}$

AQP4 has a crucial role in the regulation of the interactions occurring between endothelial and glial cells and between glial cells and the extracellular matrix components. AQP4 is a component of the orthogonal aggregate particles (OAPs), demonstrated by freeze fracturing on the ependimoglial membrane and perivascular glial endfeet, ${ }^{14}$ the development of which occurs in parallel with AQP4 glial endfeet expression and BBB maturation. ${ }^{7}$ Moreover, OAPs contain AQP4 associated with Kir $4.1^{12}$ and their polarized distribution on the glial endfeet seems to be dependent by the presence of the perivascular basement membrane. ${ }^{15}$ AQP4 controls BBB functioning, modifying

\footnotetext{
${ }^{1}$ Department of Human Anatomy and Histology, University of Bari Medical School, Bari, Italy; ${ }^{2}$ Department of Clinical Medicine, Nephrology and Health Sciences, University of Parma Medical School, Parma, Italy; ${ }^{3}$ Department of Pharmacobiology, Unit of Pharmacology, University of Bari, Bari, Italy; ${ }^{4}$ Department of Physiology and Pharmacology, University of Bari Medical School, Bari, Italy; ${ }^{5}$ Department of Internal Medicine and Clinical Oncology, University of Bari Medical School, Bari, Italy;

${ }^{6}$ Anatomy Section, Department of Medical and Morphological Research, University of Udine Medical School, Udine, Italy and ${ }^{7}$ Foundation IRCCS Neurological Institute 'C. Besta', Milano, Italy

Correspondence: Professor B Nico, Department of Human Anatomy and Histology, University of Bari Medical School, Piazza Giulio Cesare, 11, Policlinico, I-70124 Bari, Italy.

*These authors equally contribute to this work.

Received 9 March 2010; revised 1 July 2010; accepted 6 July 2010
} 
its expression and polarization when $\mathrm{BBB}$ is damaged with a consequent increase in vascular permeability and edema. ${ }^{7,16,17}$

AQP4 is also a component of the dystrophin-associated proteins (DAPs) complex, including dystroglycan (DG), syntrophin, dystrobrevin and sarcoglycans associated with dystrophin or its homolog utrophin. This complex has been extensively investigated in muscle cells, in which it is linked to the extracellular matrix of the sarcolemma, providing structural integrity during contraction. ${ }^{18}$ DAPs are also present in the glial endfeet with the short dystrophin Dp71, which is the dystrophin isoform most expressed in the brain, ${ }^{19-22}$ whereas other isoforms, such as Dp140 and the 427 full length, are, respectively, expressed by microvessels and neurons. ${ }^{1,21,23-25}$ Moreover, distribution of AQP4 and Kir 4.1 is similar to that of DAPs, ${ }^{12,26,27}$ and both proteins interact with $\alpha$-syntrophin by their postsynaptic density-95, discs large, zonula occludens-1 (PDZ) domain, establishing an important link with actin cytoskeleton. ${ }^{28,29}$

AQP4 colocalizes with $\alpha-\beta$-DG proteins, ${ }^{30}$ which, in turn, are receptors for the basement membrane proteins laminin and agrin. ${ }^{28,29,31}$ Furthermore, laminin and agrin induce AQP4 and Kir 4.1 clustering mediated by the DG complex on the glial membranes. ${ }^{30}$

DAPs and dystrophin proteins are absent or reduced in both skeletal muscle and in the brain of patients affected by Duchenne muscular dystrophy (DMD), a genetic disease caused by mutations in the X-linked dystrophin gene, and in $m d x$ mice, ${ }^{32}$ an animal model of the human disease. ${ }^{3-36}$ Besides the serious alterations affecting the neuromuscular systems, cognitive defect and brain abnormalities have also been described in a large number of DMD patients and in $m d x$ mice. $^{34,37}$

In the past, we have extensively investigated BBB alterations in $m d x$ mice, involving an increment in vascular permeability associated with structural and molecular alterations in endothelial and glial cells with AQP4 reduction and edema. ${ }^{38}$ Moreover, we have demonstrated that $m d x$ BBB alterations are coupled with a significant reduction in the short dystrophin isoform (Dp71) at glial endfeet during development, ${ }^{39}$ an increased immunoreactivity to vascular endothelial growth factor (VEGF) in neurons and to VEGF receptor-2 (VEGFR-2) in cerebral endothelial cells, ${ }^{40}$ a high expression of matrix metalloproteinases (MMPs) in the $m d x$ brain. ${ }^{41}$ Finally, we have shown that, in the brain of $m d x$ mouse, hypoxia-inducible factor- $1 \alpha$ is activated in neurons and astrocytes. ${ }^{42}$ This activation contributes through the upregulation of VEGF in neurons and of VEGFR-2 in endothelial cells, associated with a decreased expression and enhanced phosphorylation of the tight junction ZO-1 protein, to an increase in both angiogenesis and vascular permeability. ${ }^{42}$

To further elucidate the role of perivascular glial cells and their relationships with the extracellular matrix in the $m d x$ brain, in this study we have investigated the involvement of
DAPs, namely, AQP4, $\alpha-\beta$-DG, Kir 4.1, $\alpha$-syntrophin and dystrophin isoform (Dp71), and their relationship with vascular basement membrane components laminin and agrin by immunocytochemistry, confocal laser microscopy and immunogold electron microscopy. We have also evaluated their protein content and gene activity by immunoblotting and real-time polymerase chain reaction (real-time PCR).

\section{MATERIALS AND METHODS \\ Animals}

A total of 20 mice, $10 m d x$ (C57BL/10ScSn $m d x$, Jackson Laboratory, Bar Harbor, ME, USA) and 10 control mice (C57BL/10ScSn) aged 2 months, were killed by cervical dislocation; their brains were removed, divided into two parts and used in parallel for morphological and biochemical analysis. All experiments have been conformed to local and international guidelines on the ethical use of animals, and the number of animals used and their suffering have been minimized.

\section{Fixation and Preparation of Tissue}

Small pieces of brain cortex were fixed (i) in $4 \%$ paraformaldehyde in $0.1 \mathrm{M}$ phosphate buffer for immunohistochemical investigation, immunofluorescence and confocal laser microscopy; and (ii) in $0.1 \mathrm{M}$ phosphate-buffered $0.5 \%$ glutaraldehyde for the immunoelectron microscopic study. In addition, some small pieces of brain cortex were coated with OCT-mounting media and frozen in isopentane cooled by liquid nitrogen for immunofluorescence and confocal laser microscopy. Three $m d x$ and three control mice were anesthetized with pentobarbital and perfused with Ringer's, followed by $2 \%$ paraformaldehyde and $2 \%$ glutaraldehyde in $0.1 \mathrm{M}$ phosphate buffer. The brains were then removed and small pieces of brain cortex were postfixed in the same fixative for $2 \mathrm{~h}$, rinsed with $0.1 \mathrm{M}$ phosphate buffer and finally processed for electron microscopy (see below).

\section{Electron Microscopy}

The specimens were postfixed with $1 \%$ osmium tetroxide, dehydrated in an ascending ethanol series and embedded in Epon 812. Semithin sections were cut for orientation purposes and stained with toluidine blue. Thereafter, $60 \mathrm{~nm}$ ultrathin sections were cut with a diamond knife on an LKB V ultratome, stained with uranyl acetate and lead citrate and examined with a Zeiss EM109 electron microscope (Zeiss, Oberkochen, Germany).

\section{Quantitation of Perivascular Basement Membrane Thickness and Glial Endfeet Coverage}

Thirty electron micrographs at a magnification of $\times 7000$ and $\times 30000$, containing transversely cut microvessels, were chosen for each control and dystrophic mouse. On each microvessel, the number of unswollen and swollen glial endfeet, basement membrane thickness and the percentage of abluminal vascular surface covered by basement 
membrane and glial endfeet were evaluated by computeraided analysis. Morphometric analysis was performed using an electronic pen connected to a graphic tablet (Digicad Plus Kontron-Elektronic, GmbH, Germany) and to a VIDAS 2.5 computerized image analyzer (Kontron Elektronic). The mean value in each micrograph, the final mean value for all micrographs of the control and dystrophic mice, as well as s.d., were calculated. The statistical significance of the difference between the mean values of the control and dystrophic specimens was determined by Student's $t$-test.

\section{Immunogold Electron Microscopy}

Fixed specimens measuring $3 \mathrm{~mm}^{3}$ obtained from the frontoparietal brain cortex were rinsed with $10 \mathrm{mM}$ ammonium chloride in $0.1 \mathrm{M}$ PBS for $45 \mathrm{~min}$, dehydrated in an ascending ethanol series up to $70 \%$ ethanol and embedded in acrylic resin LR-Gold (London Resin, Reading, UK) with $0.8 \%$ SPIChemT Benzil (London Resin). The resin was hardened at $-25^{\circ} \mathrm{C}$ under the light of a $500 \mathrm{~W}$ halogen lamp. In all, $60 \mathrm{~nm}$-thick sections from II to IV cortical layers, previously identified on toluidine blue-stained semithin sections, were cut with an LKB V ultratome and collected on formvarcoated nickel grids. The grids were incubated for $10 \mathrm{~min}$ at room temperature with Tris-buffered saline (TBS) buffer and then treated for 4 min with $0.1 \%$ trypsin in TBS, pH 7. After rinsing with TBS, the grids were treated with $1 \%$ BSA-TBS, $\mathrm{pH}$ 7.4, for $10 \mathrm{~min}$ at room temperature to block nonspecific reactions. The sections were incubated at room temperature overnight with primary mouse anti- $\beta$-DG (Novocastra, Newcastle, UK) and mouse anti- $\alpha$-DG antibody (Chemicon International, Temecula, CA, USA) diluted 1:20, washed with TBS and incubated for $1 \mathrm{~h}$ at room temperature with secondary antibodies (goat antimouse IgG coupled to 6, 15 and $20 \mathrm{~nm}$ gold particles). The primary antibodies used in this study are listed in Table 1.

After washing with TBS, the grids were stained with $1 \%$ uranyl acetate, followed by $1 \%$ lead citrate and examined with a Zeiss EM 109 electron microscope (Zeiss). A preimmune mouse serum (Dako, Milan Italy) replacing the primary antibodies served as a negative control.

\section{Dual Immunofluorescence Confocal Laser Scanning Microscopy}

Deparaffinized brain sections and cryosectioned samples $12 \mu \mathrm{m}$ thick obtained from three $m d x$ and three control brains were used. The sections were incubated for $30 \mathrm{~min}$ in a blocking buffer (BB; phosphate-buffered saline (PBS), $\mathrm{pH} 7.4,1 \%$ bovine serum albumin, $2 \%$ fetal calf serum), and exposed to the following primary antibodies: (i) mouse antiagrin 131 monoclonal antibody (Stressgen Bioreagents, Victoria, BC, Canada) and rabbit antilaminin polyclonal

Table 2 Primer sequences for real-time PCR

$\begin{array}{ll}\text { AGR/S } & \text { 5'-CCTCGTGTCTGTGTCCTAC-3' } \\ \text { AGR/A } & \text { 5'-AAGATGTGCTCCTGGTTGG-3' } \\ \text { DG } / \mathrm{S} & 5^{\prime} \text {-GCCTTCTCCAATGXTCTG-3' } \\ \text { DG } \alpha / A & 5^{\prime} \text {-TCCTCACTGCTCTTCTCG-3' } \\ \text { LAM/S } & 5^{\prime} \text {-AAGAAGGCGACTGTAAGG-3' } \\ \text { LAM/A } & 5^{\prime} \text {-TGACTGTGGAGATGTTGG-3' } \\ \text { AQP4/S } & 5^{\prime} \text {-GAGTATGTCTTCTGTCCTG-3' } \\ \text { AQP4/AS } & 5^{\prime} \text {-ACGGTCAATGTCAATCAC-3' } \\ \text { KIR 4.1/S } & 5^{\prime} \text {-CGCTAAGGTCTATTACAGTCAG-3' } \\ \text { KIR 4.1/AS } & 5^{\prime} \text {-TGCTCCATTCTCACATTGC-3' } \\ \text { ACTIN/S } & 5^{\prime} \text {-ACCACACCTTCTACAATGAG-3' } \\ \text { ACTIN/AS } & 5^{\prime} \text {-ACGACCAGAGGCATACAG-3' } \\ \text { DG } \beta / S & 5^{\prime} \text {-AGGACACCACCACTGACAAG-3' } \\ \text { DG } \beta / A & 5^{\prime} \text {-GCATCCACAGCCGACAGG-3' } \\ \alpha S Y N / S & 5^{\prime} \text {-AAGGAGGTTGTGTGGAGGTAAG-3' } \\ \alpha S Y N / A S & 5^{\prime} \text {-GCGAGGCAGGAGGTGAGTC-3' }\end{array}$

Table 1 Primary antibodies used for immunogold electron microscopy

\begin{tabular}{|c|c|c|c|c|c|}
\hline Protein & Catalog number & Species & Dilution immunofluorescence & Dilution immunohistochemistry & Source \\
\hline$\alpha \mathrm{DG}$ & sc-53986 & Mouse & $1: 20$ & & Chemicon Int. \\
\hline Agrin & AGR-530 & Mouse & $1: 5$ & $1: 5$ & Stressgen Bio. \\
\hline Laminin & 2233PLA & Rabbit & $1: 25$ & $1: 25$ & Euro-Diagnostica \\
\hline Kir 4.1 & sc-23637 & Goat & $1: 20$ & $1: 100$ & Santa Cruz Bio. \\
\hline Dp71 (pan-specific antibody) & MANDRA1 & Mouse & $1: 20$ & & Sigma \\
\hline$\alpha$-Syntrophin & sc-13757 & Goat & $1: 20$ & & Santa Cruz Bio. \\
\hline
\end{tabular}


antibody (Euro-Diagnostica, Malmö, Sweden), diluted 1:5 and 1:25, respectively, in $\mathrm{BB}$ overnight at $4{ }^{\circ} \mathrm{C}$; (ii) rabbit anti-AQP4 (Santa Cruz Biotechnology) and goat anti-Kir 4.1 (Santa Cruz Biotechnology) polyclonal antibodies diluted $1: 25$ and $1: 20$, respectively, in $\mathrm{BB}$ overnight at $4{ }^{\circ} \mathrm{C}$; (iii) mouse anti-agrin-131 and goat anti-Kir 4.1 antibodies diluted 1:10 and 1:50, respectively, in BB; (iv) rabbit anti-AQP4 and mouse anti- $\beta$-DG monoclonal antibodies (Novocastra) diluted 1:50 and 1:500, respectively, in $\mathrm{BB}$ overnight at $4{ }^{\circ} \mathrm{C}$; (v) rabbit anti-AQP4 and mouse anti- $\alpha$-DG monoclonal primary antibodies (Chemicon International) diluted 1:100 and 1:20, respectively, in $\mathrm{BB}$ overnight at $4{ }^{\circ} \mathrm{C}$; (vi) rabbit anti-AQP4 and mouse antidystrophin isoform (Dp71) (Mandra 1, Sigma) diluted 1:25 and 1:20, respectively, in $\mathrm{BB}$ overnight at $4{ }^{\circ} \mathrm{C}$. Mandra 1 antibody strongly stains the full-length dystrophin in the muscle, whereas in the brain it recognizes the $71-\mathrm{kDa}$ protein; ${ }^{22}$ (vii) rabbit anti-AQP4 and goat anti- $\alpha$-syntrophin (Santa Cruz Biotechnology) diluted 1:25 and 1:50, respectively, in $\mathrm{BB}$ overnight at $4{ }^{\circ} \mathrm{C}$. After washing in PBS, the sections were incubated for $2 \mathrm{~h}$ with the following secondary antibodies: (i) Alexa Fluor 488 goat antimouse (Invitrogen, Carlsbad, CA, USA) and Alexa Fluor 555 goat antirabbit antibodies (Invitrogen) diluted 1:300 in $\mathrm{BB}$ for agrin and laminin dual localization; (ii) Alexa Fluor 488 goat antirabbit and Alexa Fluor 568 donkey antigoat (Invitrogen) antibodies diluted 1:200 and 1:300 in BB, respectively, for AQP4 and Kir 4.1 and AQP4 and $\alpha$-syntrophin dual localization; (iii) Alexa Fluor 555 goat antimouse antibody diluted 1:300 and Alexa Fluor 488 donkey antigoat antibody diluted 1:200 for agrin and Kir 4.1 dual localization; (iv) Alexa Fluor 555 goat antirabbit and Alexa Fluor 488 goat antimouse diluted 1:400 in BB for AQP4 and $\beta$-DG dual localization; (v-vi) Alexa Fluor 555 goat antirabbit and Alexa Fluor 488 goat antimouse diluted $1: 300$ and 1:200, respectively, in BB for AQP4 and $\alpha$-DG, AQP4 and dystrophin isoform (Dp71) dual localization. All samples were incubated for $5 \mathrm{~min}$ with $0.01 \%$ TO-PRO-3 (Invitrogen) for nuclear staining and mounted in Vectashield (Vector Laboratories, Burlingame, CA, USA). Negative controls, obtained by substituting primary antibodies with normal mouse serum for agrin, $\alpha-\beta$-DG and dystrophin isoform (Dp71), substituting normal rabbit serum for laminin and AQP4 (Santa Cruz Biotechnology) and normal goat serum for Kir 4.1 and $\alpha$-syntrophin (Chemicon International), showed no staining of the sections. The sections were examined under a Leica TCS SP2 (Leica, Wetzlar, Germany) confocal laser scanning microscope using $40 \times$ and $63 \times$ objective lenses with either $1 \times$ or $2 \times$ zoom factors. A sequential scan procedure was applied during image acquisition of the two fluorophores. Confocal images were taken at $200 \mathrm{~nm}$ intervals through the $z$ axis of the section covering a total depth of $10 \mu \mathrm{m}$. Images from individual optical planes and multiple serial optical sections were analyzed, digitally recorded and stored as TIFF files using Adobe Photoshop software (Adobe Systems, San Jose, CA, USA).

\section{Laminin, Agrin, Kir 4.1 and AQP4 Immunohistochemistry} Histological sections of $5 \mu \mathrm{m}$ thickness, collected on polyL-lysine-coated slides (Sigma Chemical, St Louis, MO, USA), were deparaffinized and stained with a three-layer avidinbiotin-immunoperoxidase system technique. The sections were rehydrated in a xylene-graded alcohol scale and then rinsed for $10 \mathrm{~min}$ in $0.1 \mathrm{M}$ PBS. For laminin immunodetection, sections were treated with $2.5 \%$ ficin (Sigma Chemical) in PBS for $5 \mathrm{~min}$ at $37^{\circ} \mathrm{C}$, and then exposed to polyclonal rabbit anti-laminin (Euro Diagnostica, Malmö, Sweden) diluted 1:25, in PBS overnight at $4{ }^{\circ} \mathrm{C}$. For agrin, Kir 4.1 and AQP4 immunodetection, the sections were incubated, respectively, with monoclonal mouse anti-agrin-131 (Stressgen Bioreagents, Victoria, BC, Canada), polyclonal goat anti-Kir 4.1 and polyclonal rabbit anti-AQP4 (Santa Cruz Biotechnology), primary antibodies diluted 1:5, 1:100, 1:25, respectively, in $\mathrm{PBS}$ overnight at $4{ }^{\circ} \mathrm{C}$. After $3 \times 5 \mathrm{~min}$ washings in PBS, the sections were incubated with biotinylated swine antimouse, rabbit and goat Ig (Multi-Link, Dako, Milan) diluted 1:150 in PBS for $1 \mathrm{~h}$ at room temperature, and with streptavidin-peroxidase conjugate (Dako) diluted 1:150 in PBS for $30 \mathrm{~min}$ at room temperature. Immunodetection was performed in distilled water with AEC substrate kit for peroxidase (Vector Laboratories) for $40 \mathrm{~min}$ at room temperature. Thereafter, the sections were washed in distilled water, counterstained with Gill's hematoxylin number 2 (Polysciences, Warrington, PA, USA) and mounted in buffered glycerin. Specific preimmune serum (Dako) replacing the primary antibodies served as a negative control.

\section{Real-Time PCR}

cDNA was amplified with iTaq SYBR Green supermix using a ROX kit (Bio-Rad Laboratories, Hercules, CA, USA) and PCR amplification was performed using the Chromo4 real-time PCR Detection System (Bio-Rad Laboratories). The expression of messengers for agrin, $\alpha-\beta-D G$, laminin, AQP4, Kir 4.1, $\alpha$-syntrophin and actin as housekeeping gene was evaluated by real-time PCR. The primer sequences, all with $60{ }^{\circ} \mathrm{C}$ of annealing temperature (Operon Biotechnologies $\mathrm{GmbH}$, Cologne, Germany), are reported in Table 2.

The amplification process includes 40 cycles, each consisting of these three steps: (i) incubation at $95^{\circ} \mathrm{C}$ for $3 \mathrm{~min}$; (ii) incubation at $95^{\circ} \mathrm{C}$ for $15 \mathrm{~min}$; and (iii) annealing and extension at $60^{\circ} \mathrm{C}$ for $30 \mathrm{~min}$. Therafter, the last cycle, the melting curves analysis, was performed at $55-95^{\circ} \mathrm{C}$ interval by increasing the temperature by $0.5^{\circ} \mathrm{C}$. The fold change values were calculated according to the Pfaffl method. ${ }^{43}$

\section{Western Blot}

Brains of three $m d x$ and three control mice were homogenized with a Polytron apparatus in a lysis buffer containing $20 \mathrm{mM}$ Tris $\mathrm{HCl} \mathrm{pH} \mathrm{7.5,} \mathrm{1 \%} \mathrm{Triton} \mathrm{X-100,} \mathrm{1 \%} \mathrm{NP-40,} 2 \mathrm{mM}$ $\mathrm{MgCl} 2,5 \mathrm{mM}$ EDTA, $150 \mathrm{mM} \mathrm{NaCl}, 0.2 \mathrm{mM}$ phenyl-

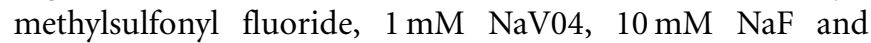
protease inhibitors. After centrifugation at $1000 \mathrm{~g}$ for $10 \mathrm{~min}$, 

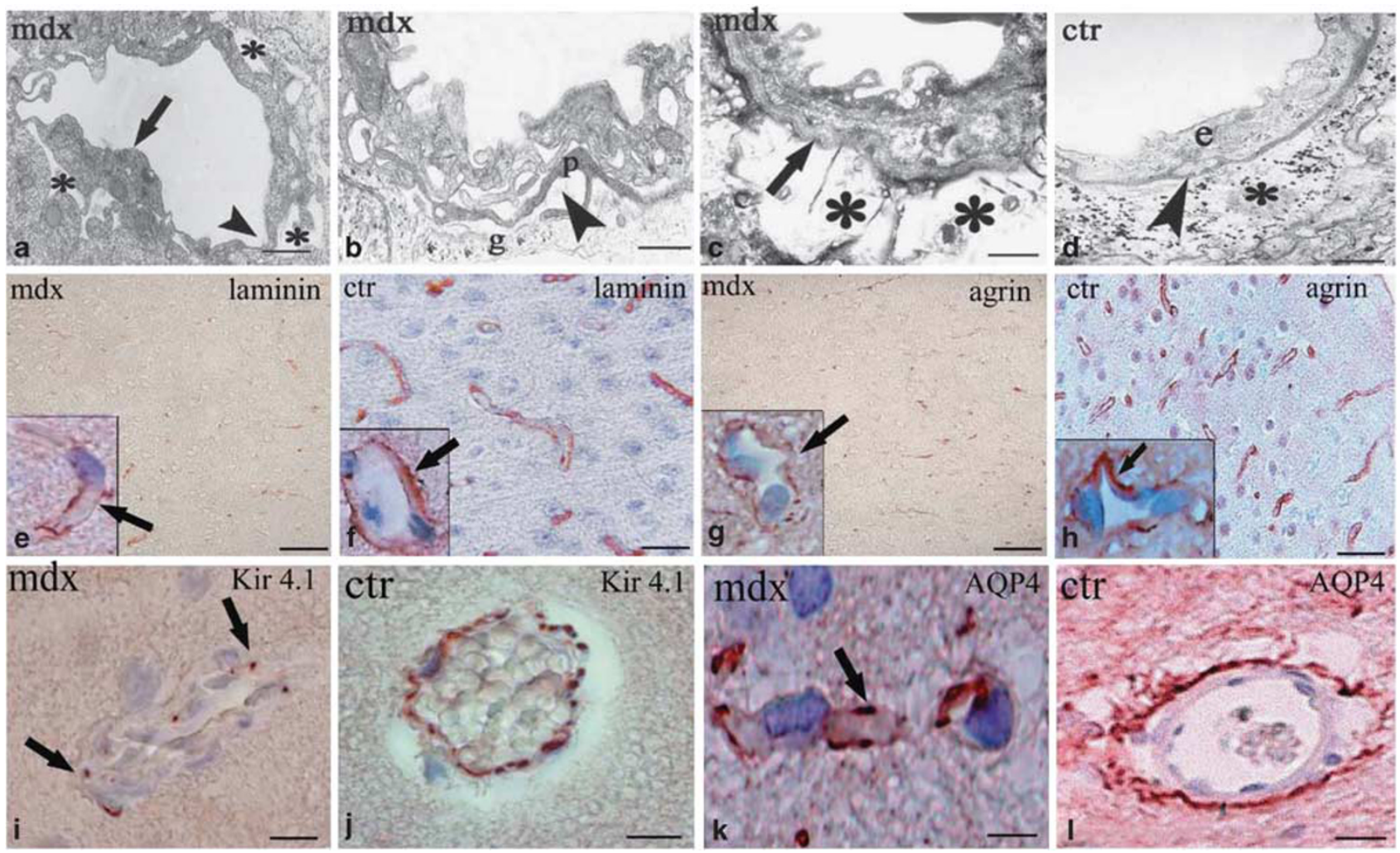

Figure 1 (a-d) Ultrastructural analysis of $m d x(\mathbf{a}-\mathbf{c})$ and control (d) vessels. (a-c) Mdx vessels lined by irregular endothelium alternating thick (a, arrow) and thin cytoplasmic regions (arrowhead), surrounded by perivascular spaces (a, asterisk), subtended by discontinuous basement membrane, lacking in some tracts, (b, arrowhead) in which a glial endfoot $(\mathrm{g})$ faces a pericyte protrusion (p). (c) Mdx vessel subtended by thickened basement membrane (arrow) enveloped by a swollen glial endfoot (asterisk). (d) Control vessel lined by flattened endothelial cells (e) and surrounded by a continuous basement membrane (arrowhead) and glial endfoot containing glycogen granules (asterisk). (e-h) Immunohistochemical expression of laminin and agrin in $m d x$ (e, $\mathbf{g}$ ) and control (f, $\mathbf{h})$ vessels. Laminin $(\mathbf{e}, \mathbf{f})$ and agrin $(\mathbf{g}, \mathbf{h})$ are faintly and discontinuously expressed on the abluminal sides of mdx vessels (e, $\mathbf{g}$ insets, arrows) and strongly expressed in the control ones (f, $\mathbf{h}$ insets, arrows). (i-I) Immnunohistochemical expression of Kir 4.1 and AQP4 in $m d x(\mathbf{i}, \mathbf{k})$ and control $(\mathbf{j}, \mathbf{I})$ vessels. (i, $\mathbf{k}) M d x$ vessels display a discontinuous and puntiform staining (i, arrow) for Kir 4.1 and rod (k, arrow) for AQP4 proteins. (I, n) Control vessels intensely and uniformly labeled by antibodies anti-Kir 4.1 (j) and anti-AQP4 (I) proteins. Scale bar: a, $0.57 \mu \mathrm{m} ; \mathbf{b}-\mathbf{d}, 0.33 \mu \mathrm{m} ; \mathbf{e}, \mathbf{g}, \mathbf{h}, 50 \mu \mathrm{m} ; \mathbf{f}, 40 \mu \mathrm{m} ; \mathbf{e}-\mathbf{h}$ inset $25 \mu \mathrm{m} ; \mathbf{i}-\mathbf{k}, 12.5 \mu \mathrm{m}$.

the protein concentration of the supernatant was determined using the detergent compatible Bio-Rad DC protein assay (Bio-Rad Laboratories). For immunoblotting, $60 \mu \mathrm{g}$ per lane of protein extract was solubilized in Laemmli buffer, boiled at $90^{\circ} \mathrm{C}$ for $5 \mathrm{~min}$ and resolved on a $7.5 \%$ polyacrylamide gel; thereafter, the proteins were electrotransferred to a nitrocellulose membrane (Amersham Bioscience, Buckinghamshire, UK). Blots were blocked with PBS BB containing 5\% non-fat dry milk for $1 \mathrm{~h}$ and incubated for $2 \mathrm{~h}$ with the following primary antibodies: rabbit anti-AQP4 (Chemicon) diluted 1:1000, rabbit anti-Kir 4.1 (Chemicon) diluted 1:400, mouse anti- $\alpha$-DG diluted 1:200 (Santa Cruz), mouse anti$\beta$-DG diluted 1:50 (Novocastra), mouse anti-agrin-131 (Stressgen Bioreagents) diluited 1:1000, goat anti- $\alpha$-syntrophin (Santa Cruz Biotechnology) diluted 1:1000, mouse anti-Dp71 (Clone Mandra 1-Sigma Aldrich), and mouse anti- $\beta$-actin (Santa Cruz) diluted 1:1000. After the primary antibody treatment, the membranes were washed $4 \times$ for 5 min each at RT in PBS $+0.1 \%$ Tween- 20 before the addition of secondary antibodies. PBS and $0.1 \%$ Tween-20diluted secondary antibodies (antimouse, rabbit and goat) were IRDye labeled (680/800CW) (LI-COR Biosciences, Lincoln, NE, USA). For immunoblot analysis, the Li-cor Odyssey infrared imaging system was used (LI-COR).

The western blot images were analyzed by imaging densitometry using Quantity One Software (Bio-Rad Laboratories) and compared with actin. The data were expressed as optical density $\times \mathrm{mm}^{2}$.

\section{RESULTS}

\section{Electron Microscopy}

In $m d x$ brain, vessels showed ultrastructural alterations. They were lined by irregular endothelium, alternating thin and thick cytoplasmic regions containing vesicles and vacuoles (Figure 1a). The endothelial abluminal side was subtended by a discontinuous basement membrane enveloping pericytes, or lacked it (Figure 1b), and was surrounded by large perivascular spaces (Figure 1a, asterisk), or displayed 

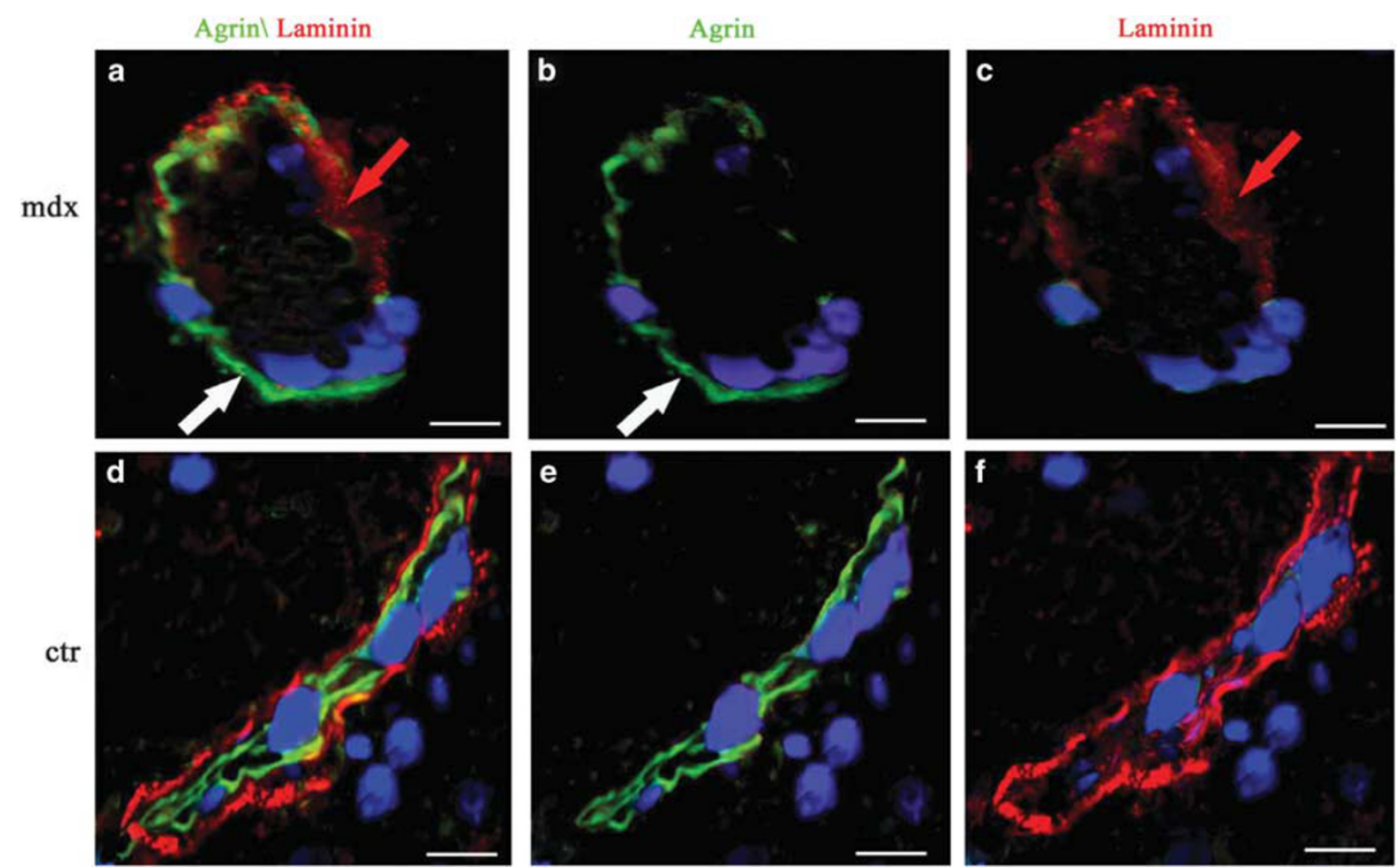

Figure 2 Confocal dual immunofluorescence reaction of agrin (green) and laminin (red) in $m d x(\mathbf{a}-\mathbf{c})$ and control vessels (d-f). (a-c) $M d x$ vessel showing a discontinuous expression of both agrin (green) and laminin (red), with tract expressing both proteins (a, red arrow), and others expressing only agrin (a, b, arrow) or laminin (a, c, red arrow). (d-f) Control vessel showing a continuous green and red signal of both proteins for its entire surface. Scale bar: $\mathbf{a}-\mathbf{f}$, $15.8 \mu \mathrm{m}$.
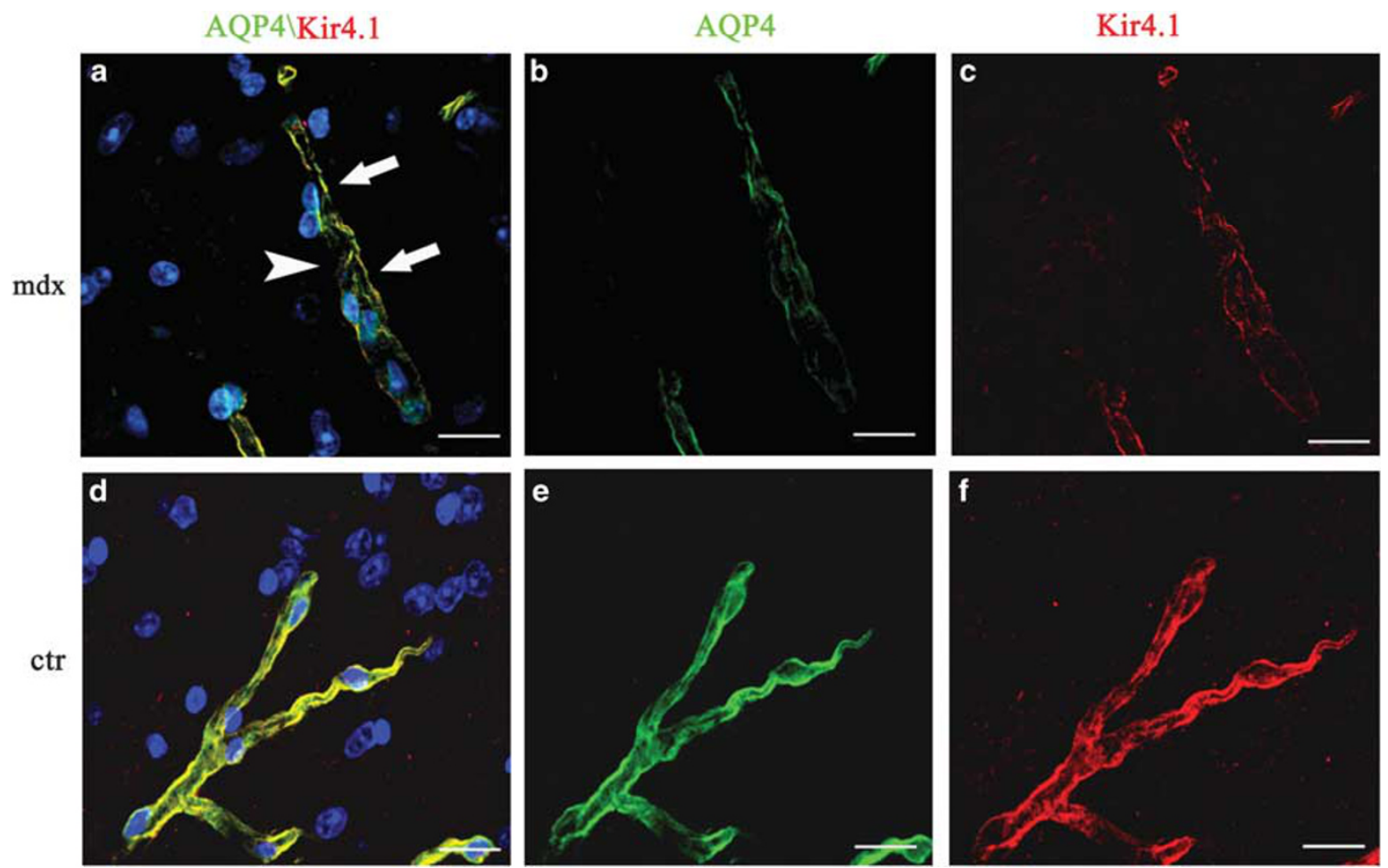

Figure 3 Confocal dual-immunofluorescence reaction of AQP4 (green) and Kir 4.1 (red) in $m d x(\mathbf{a}-\mathbf{c})$ and control vessels (d-f). (a, c) A light merge orange signal of colocalizing AQP4 and Kir 4.1 is detectable along an $m d x$ vessel (a, arrow), in which labeled tracts alternate with unlabeled ones (a, arrowhead). (d-f) An intense orange staining of both AQP4 and Kir 4.1 is present along the entire vascular wall. Scale bar: a-f, $25 \mu \mathrm{m}$.

a thick basement membrane facing the perivascular glial endfeet (Figure 1c), whereas in controls, the vessels were lined by regularly flattened endothelial cells and by continuous basement membrane (Figure 1d). In $m d x$ brain, the perivascular glial coverage was reduced and modified, because some vessels were only partially enveloped by 

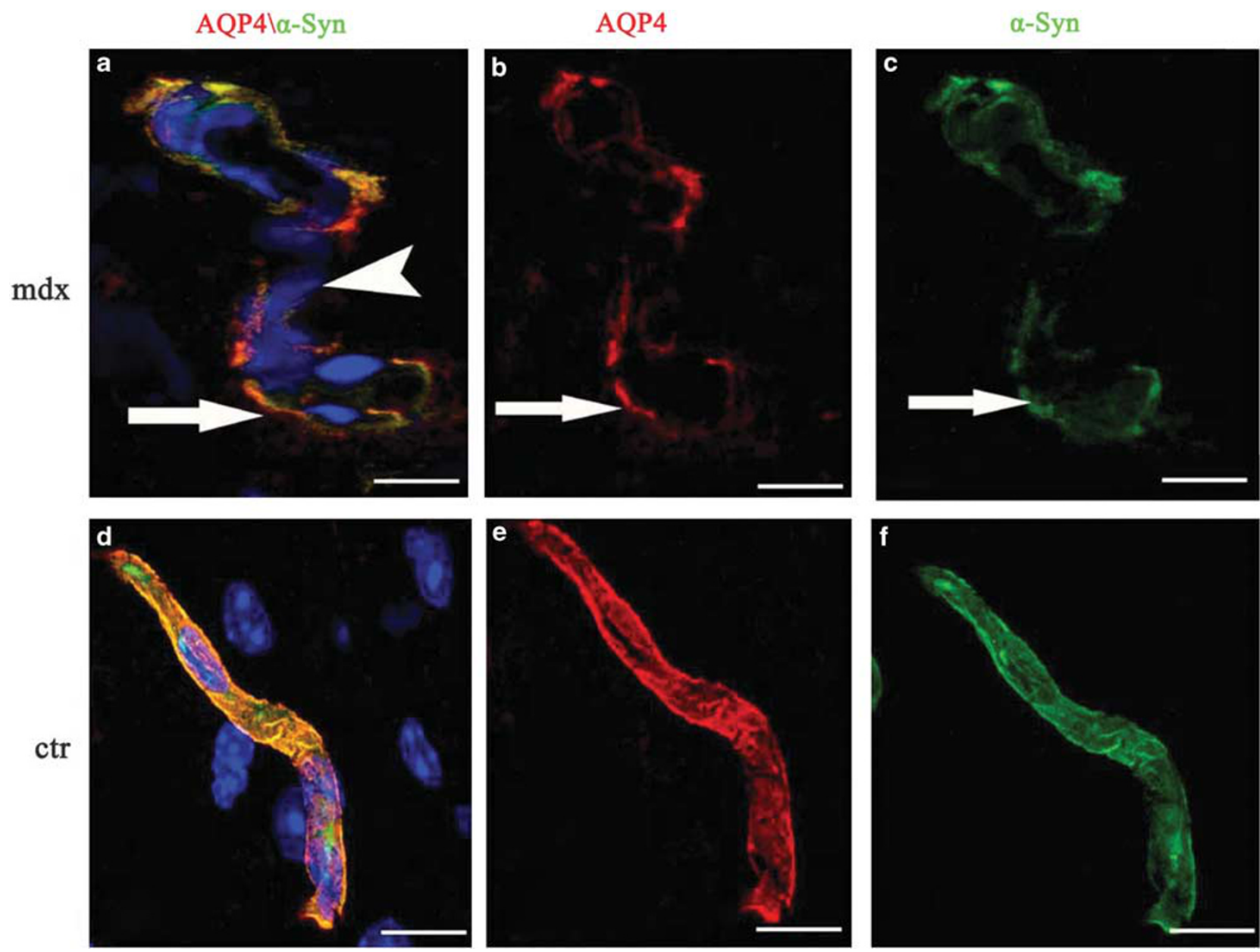

Figure 4 Confocal dual immunofluorescence reaction of AQP4 (red) and $\alpha$-syntrophin ( $\alpha$-Syn) (green) in $m d x(\mathbf{a}-\mathbf{c})$ and control vessels (d-f). The vessels show a merge fluorescence signal of AQP4 and $\alpha$-syntrophin colocalization, which is light and discontinuous along the mdx vascular surface (a-c) and strongly uniform in the control one (d-f). Note in (a) (arrowhead), unlabeled vessel tract alternates with orange tracts expressing both AQP4 and $\alpha$-syntrophin (a-c arrow). Scale bar: a-c, $15.8 \mu \mathrm{m} ; \mathbf{d}-\mathbf{f}, 25 \mu \mathrm{m}$.

glial endfeet, swollen and devoid of glycogen granules and organelles (Figure 1c), and other ones were surrounded by enlarged, apparently empty, perivascular spaces (Figure 1a). In controls, a flat sheath of glial endfeet characterized by electron-lucent cytoplasm containing glycogen granules entirely covered the vascular wall (Figure 1d).

Morphometric analysis showed that the basement membrane was thicker and covered only $43 \%$ of the abluminal vascular surface in mdx mice as compared with control ones (Table 1). Moreover, the number of swollen glial endfeet and the percentage of abluminal vascular surface covered by glial endfeet were significantly higher and, respectively, lower in the $\mathrm{mdx}$ mouse as compared with the control one (Table 1).

\section{Laminin and Agrin Expression}

In $m d x$ brain, some tracts of the vessel wall were completely devoid of laminin (Figure 1e) or agrin (Figure 1g), whereas others were faintly labeled (Figures 1e and g insets, arrow). In controls, the abluminal side of the vessel wall was uniformly stained by both anti-laminin and anti-agrin antibodies, as shown in Figures if and $\mathrm{h}$ (at low and high magnification (insets, arrow).

After dual confocal immunofluorescence reaction, in $m d x$ brain, the vessel wall showed a discontinuous expression of both agrin and laminin and only short tracts expressed both proteins (Figures $2 \mathrm{a}-\mathrm{c}$ ), whereas other tracts appeared unlabeled, or expressed only agrin (Figure $2 \mathrm{~b}$ ) or laminin (Figure 2c). In controls, both proteins showed a separate signal and a continuous staining pattern (Figures $2 \mathrm{~d}-\mathrm{f}$ ).

\section{AQP4, Kir 4.1 and $\alpha$-Syntrophin Expression}

In $m d x$ brain, a discontinuous rod AQP4 staining (Figure 1k) and a faint and puntiform expression of Kir 4.1 (Figure 1i) were recognizable on the abluminal side of the vessel wall. On the contrary, in controls, both AQP4 and Kir 4.1 showed an intense and uniform staining (Figures $1 \mathrm{j}$ and $\mathrm{l}$ ). 

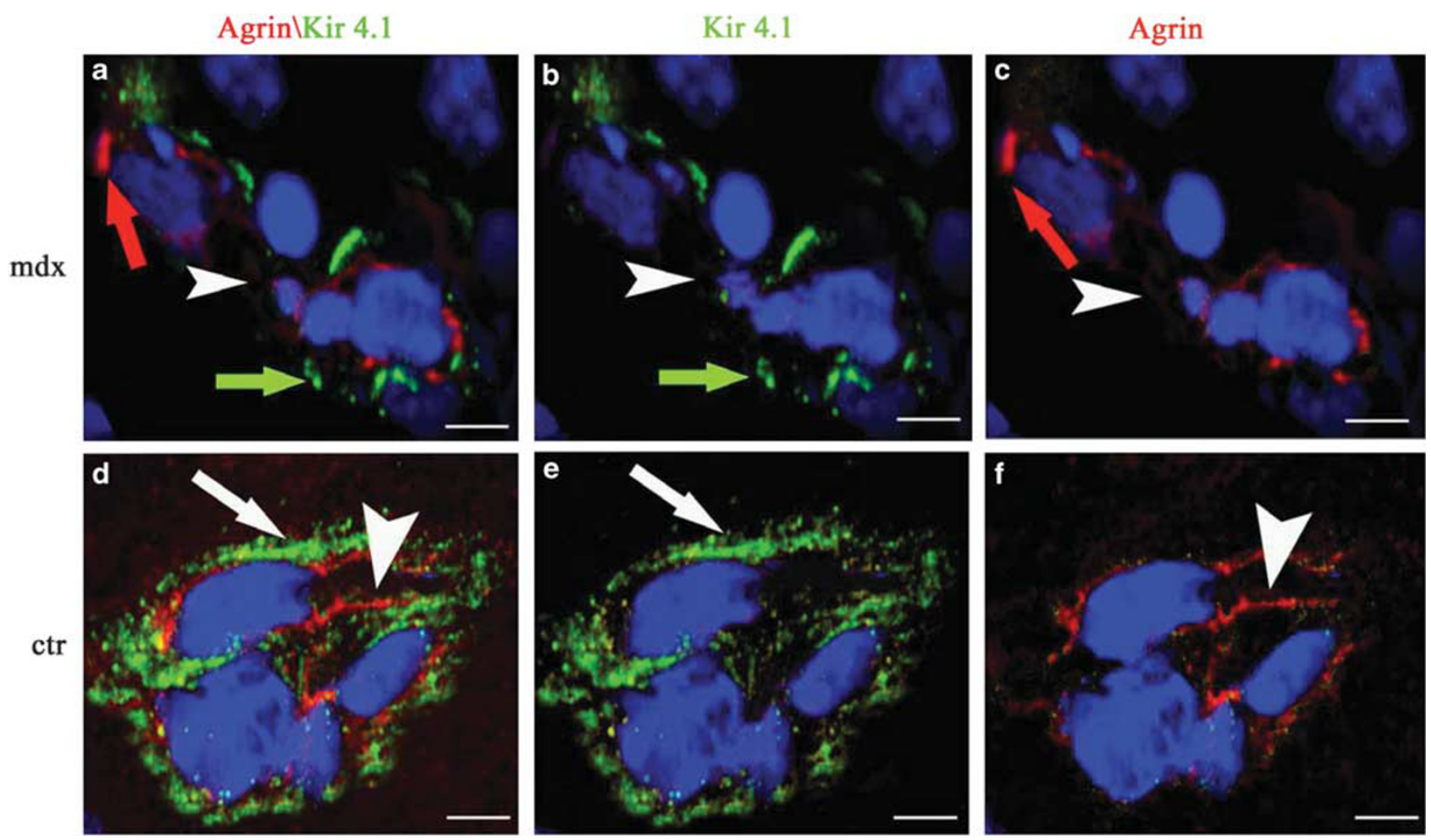

Figure 5 Confocal dual immunofluorescence reaction of agrin (red) and Kir 4.1 (green) in $m d x(\mathbf{a}-\mathbf{c})$ and control vessels (d-f). A red fluorescence signal separated by a green signal is present around the vessels with a discontinuous dotted ( $\mathbf{a}, \mathbf{b}$ green arrow) and rod ( $\mathbf{a}, \mathbf{c}$ red, arrowhead) pattern expression in the $m d x$ vessel $(\mathbf{a}-\mathbf{c})$ and with an intensely uniform expression for both Kir 4.1 (d, e, arrow) and agrin (d, $\mathbf{f}$, arrowhead) in controls. Note in panels $\mathbf{a}, \mathbf{b}, \mathbf{c}$ (arrowhead), vessel tract lacking both Kir 4.1 green and agrin red signal. Scale bar: a-f, $15.8 \mu \mathrm{m}$.

After dual confocal immunofluorescence reaction of AQP4 and Kir 4.1, in $m d x$ brain, only some vascular tracts showed a merge fluorescent signal of colocalization, whereas other tracts were devoid of both AQP4 and Kir 4.1 signals (Figures $3 \mathrm{a}-\mathrm{c}$ ). In controls, an orange intense staining, indicating expression of a colocalization of both proteins, was recognizable along the entire vascular wall (Figures $3 \mathrm{~d}$ and e).

The same pattern of expression and the same difference between $m d x$ and control brain were detectable after dual confocal immunofluorescence reaction between AQP4 and $\alpha$-syntrophin proteins, showing a light merge colocalization signal in short vessel tracts alternating with unlabeled ones in the $m d x$ brain (Figures $4 \mathrm{a}-\mathrm{c}$ ) and a strong and continuous orange signal throughout the vessel surface in the control ones (Figures $4 \mathrm{~d}-\mathrm{f}$ ).

\section{Kir 4.1 and Agrin Expression}

In $m d x$ brain, a reduction in both Kir 4.1 and agrin separate fluorescence was observed, and Kir 4.1 green signal was lost in the same vascular tracts in which agrin fluorescence signal was absent (Figures $5 \mathrm{a}-\mathrm{c}$ ). In controls, an intense fluorescence signal of both Kir 4.1 and agrin, which were uniformly expressed, but not colocalized around the vessel wall, was recognizable (Figures 5d-f).

\section{AQP4 and $\alpha-\beta$-DG Expression}

In $m d x$ brain, AQP4 and $\alpha-\beta$-DG were not completely colocalized along the abluminal surface, with some tracts in which both proteins displayed a separate expression and others showing light and discontinuous merge fluorescence (Figures $6 \mathrm{a}-\mathrm{c}$, for $\alpha$-DG and Figures $7 \mathrm{a}-\mathrm{c}$, for $\beta$-DG). Differently in controls, AQP4 and $\alpha-\beta$-DG showed a continuous and intense orange fluorescence signal (Figures $6 \mathrm{~d}-\mathrm{f}$ for $\alpha-D G$ and Figures $7 \mathrm{~d}-\mathrm{f}$ for $\beta$-DG) for the entire vessel surface.

\section{$\alpha$ - $\beta$-DG Immunogold Electron Microscopy}

In $m d x$ brain, both $\alpha$ - and $\beta$-DG gold particles were scattered in the cytoplasms of swollen glial endfeet (Figures 8a and c), whereas rare gold particles were observed attached to the glial membrane enveloping subendothelial basement membranes. In controls, numerous gold particles of both $\alpha$ - and $\beta$-DG were attached on the glial membranes facing the basement membrane (Figures $8 \mathrm{~b}$ and $\mathrm{d}$ ).

\section{AQP4 and Dystrophin Isoform (Dp71) Expression}

In $m d x$ brain, the vessels displayed a merge fluorescent signal with a reduction in both dystrophin isoform (Dp71) green and AQP4 red staining on the abluminal sides (Figures 9a-c). In controls, vessels showed a strong orange fluorescence with a uniform expression of both proteins, which colocalized in 

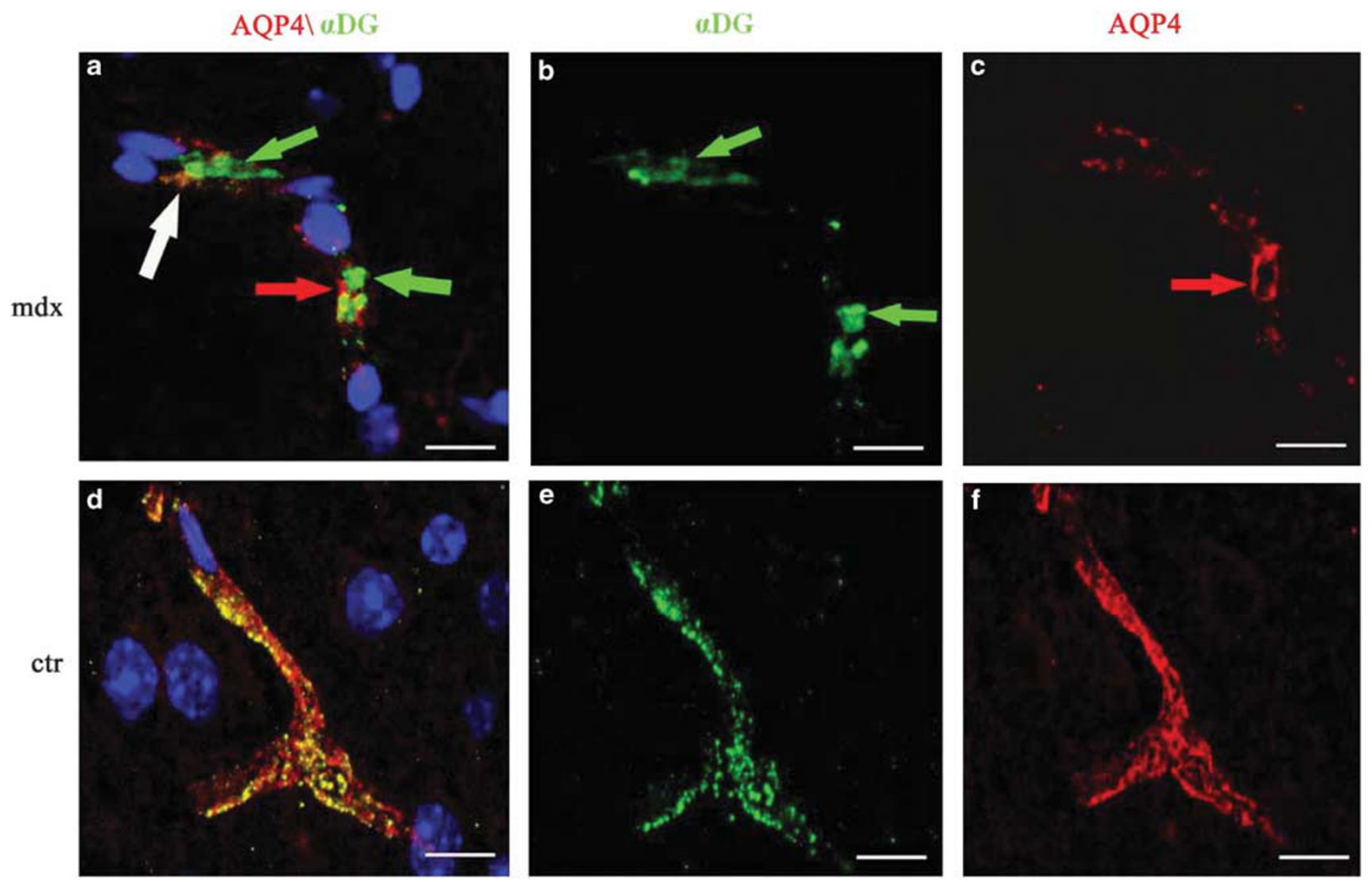

Figure 6 Confocal dual immunofluorescence reaction of AQP4 (red) and $\alpha$-DG (DG, green) in $\mathbf{m d x}(\mathbf{a}-\mathbf{c})$ and control vessels (d-f). (a-c) AQP4 red and $\alpha$-DG green fluorescence showed a light orange colocalizing signal in a short $m d x$ vessel tract (a, arrow) and a separate AQP4 (a, c, red arrow) and $\alpha$-DG $(\mathbf{a}, \mathbf{b}$, green arrow) signal in other tracts. (d-f) A uniformly orange fluorescence is present along the entire control vessel surface. Scale bar: $\mathbf{a}-\mathbf{f}, 25 \mu \mathrm{m}$.

the perivascular glial endfeet (Figures $9 \mathrm{~d}-\mathrm{f}$ ). Table 3 shows quantitation of alterations in perivascular glial endfeet and basement membrane in $\mathrm{mdx}$ and control brain.

\section{Real-Time PCR Analysis}

We investigated the messenger expression of both DAP genes AQP4, Kir 4.1, $\alpha-\beta$-DG, $\alpha$-syntrophin and laminin and agrin in $m d x$ and control brain. As we found by real-time PCR experiment (Figure 10a), the entire messenger analyzed was downregulated in $m d x$ brains with respect to controls.

\section{Western Blotting Analysis}

To study whether the altered gene expression observed in $m d x$ mice leads to a protein level variation, we performed a western blotting analysis of DAPs AQP4, $\alpha-\beta$-DG, Kir 4.1, syntrophin and laminin and agrin in $m d x$ and control brains. The result of the experiment showed a significant downregulation of all $m d x$ brain analyzed proteins with respect to controls (Figure 10b). Further, the level of the short dystrophin isoform (Dp71) protein in mice was lower in $m d x$ brain as compared with the control one (Figure 10c).

\section{DISCUSSION}

In this study, we have demonstrated for the first time that in the brain of $m d x$ mice, glial cells showed a significant reduction in both protein and mRNA content of the DAPs, including AQP4, Kir 4.1, syntrophin and $\alpha-\beta$-DG, coupled with a decrease in dystrophin isoform (Dp71). Moreover, we have shown alterations of the vascular basement membrane and reduction of the expression of its components laminin and agrin and translocation of $\alpha-\beta$-DG receptors in the glial cytoplasmic endfeet.

DAP complexes, including AQP4, Kir 4.1 protein, DG and syntrophin, are a group of proteins that link the cytoskeleton to the extracellular matrix. In the brain, they are mainly expressed in perivascular astrocytes and in choroid plexuses, suggesting a potential role in water homeostasis, regulation of transport mechanisms across BBB and cerebrospinal fluid production. ${ }^{7,10,19,31,39,44}$ Mutations of DAPs are involved in muscular dystrophy, ${ }^{45}$ and are responsible for structural and biochemical changes in the brain. ${ }^{46}$ The dystrophin isoform Dp71 is localized in the perivascular glial endfeet, in which it is involved in BBB maturation ${ }^{39,47}$ and in the clustering of the AQP4 water channel on the astrocyte glial membranes. ${ }^{48}$ 



Figure 7 Confocal dual immunofluorescence reaction of AQP4 (red) and $\beta$-dystroglycan (DG) (green) in $m d x(\mathbf{a}-\mathbf{c})$ and control vessels (d-f). (a-c) Mdx vessel showing an orange fluorescence of AQP4 and $\beta$-DG coexpression (a, arrow) alternating with unlabelad areas, $(\mathbf{a}$, arrowhead). A green $\beta$-DG fluorescence (a, $\mathbf{c}$ green arrow) separated by a red AQP4 fluorescence $(\mathbf{a}, \mathbf{b})$ is well evident along a vessel tract. (d-f) Control vessel showing a strong merge fluorescence of AQP4 and $\beta$-DG colocalization. Scale bar: a-f, $25 \mu \mathrm{m}$.

AQP4 controls BBB functioning and integrity, because its expression parallels $\mathrm{BBB}$ development and is altered after BBB damage. ${ }^{7,49}$ AQP4 expression on the perivascular processes of astrocytes is correlated to the ability of astrocytes to remove $\mathrm{K}^{+}$excess from the extracellular clefts by active and passive uptake and $\mathrm{K}^{+}$flux. ${ }^{13,50}$ Nagelhus et al ${ }^{9}$ demonstrated that Müller cells showed higher AQP4 content in the astrocytic endfoot and that the distribution of AQP4 was coupled with the $\mathrm{K}^{+}$channel protein Kir 4.1. This latter clustered on glial membranes only in the presence of Dp71. ${ }^{48}$ In fact, in the retina of Dp71 knockout mice, both AQP4 and Kir 4.1 expression levels are decreased and mislocated around blood vessels. ${ }^{51}$

AQP4 is also associated with Kir 4.1 and with other components of DAPs, ${ }^{28,48}$ such as $\alpha$-syntrophin, which anchored AQP4 in a polarized way on the astrocytic membranes facing the vessels by interaction of its PDZ domain with the C-terminal SSV residues of AQP4. ${ }^{13,52,53}$ Furthermore, $\alpha$-syntrophin-null mice showed AQP4 reduction and redistribution and delayed $\mathrm{K}^{+}$clearance, ${ }^{13,31}$ suggesting that a correct link between AQP4 proteins and DAPs is necessary for an efficient $\mathrm{K}^{+}$removal.

In accordance with these data, in this study, we have found in control mice by dual confocal immunofluorescence that AQP4 colocalized with Kir 4.1 and $\alpha$-syntrophin and with dystrophin isoforms (Dp71) and that these proteins were strongly expressed by perivascular glial endfeet, which uniformly enveloped the vessel wall. Even if the antibody used in our study is considered a pan-specific antibody that recognizes only Dp71 in brain, which recognizes all the DMD gene products, we have demonstrated by immunoblotting that, in the brain, this antibody recognized specifically the short isoform Dp71, with a significant reduction in its content in the $m d x$ mouse, as demonstrated by Lederfein et al. ${ }^{22}$

Otherwise, we demonstrated for the first time in dystrophic vessels a parallel decrease in all these proteins, showing a significant reduction at both transcriptional and transductional levels, and a faint and discontinuous expression by perivascular glial endfeet. These results confirm the functional interaction of these proteins, as has been 

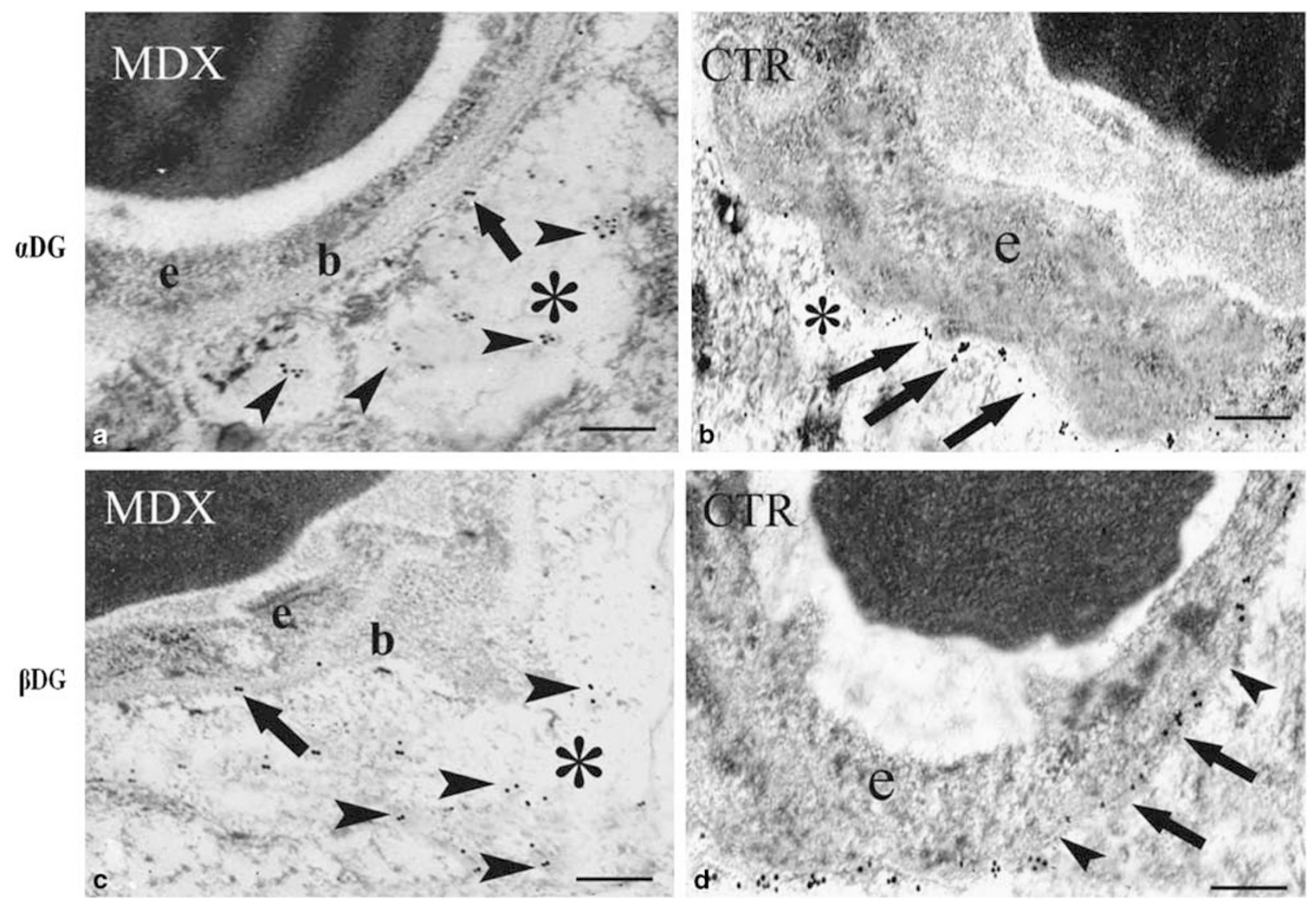

Figure 8 Immunogold electron microscopy showing ultracytochemical localization of $\alpha$-dystroglycan (DG) and $\beta$-DG in mdx (a-c) and control (b-d) vessels. $(\mathbf{a}, \mathbf{c}) m d x$ vessels showing $\alpha$-DG (a, arrowhead) and $\beta$-DG (c, arrowhead) gold particles scattered in the cytoplasms of swollen glial endfeet (a, $\mathbf{c}$, asterisk). Note isolated gold particles of both $\alpha$-DG (a, arrow) and $\beta$-DG (c, arrow) attached on the glial membranes facing the thick basement membrane (b), enveloping endothelial cells (e). (b, d) Control vessels showing numerous $\alpha$-DG (b, arrow) and $\beta$-DG (d, arrow) gold particles decorating the glial endfeet (b, asterisk) facing the thin basement membrane (d, arrowhead) enveloping the vessels. e, endothelial cell. Scale bar: $\mathbf{a}-\mathbf{c}, 0.21 \mu \mathrm{m} ; \mathbf{d}, 0.16 \mu \mathrm{m}$.

demonstrated in other brain diseases. ${ }^{54}$ Moreover, we have observed that even if AQP4 and Kir 4.1 reduced their protein content, they maintained a polarized expression on the perivascular glial endfeet, suggesting that a similar molecular mechanism is involved in membrane clustering for both proteins. Otherwise, in the retina of Dp71-null mice, AQP4 expression was reduced, whereas Kir 4.1 expression was unaffected, ${ }^{11}$ and the deletion of $\alpha$-syntrophin gene caused AQP4 reduction of AQP4 in Muller cells, but not of Kir 4.1. ${ }^{55}$ These discrepancies could be explained by the fact that, in the $m d x$ brain, 427 full-length dystrophin alone was completely lost, whereas the other isoforms, including Dp71 and syntrophin, were decreased, but preserved their link with AQP4 and Kir 4.1.

Moreover, we have previously demonstrated in $m d x$ brain a significant reduction of AQP4 and dystrophin isoform (Dp71) in the glial endfeet in $m d x$ embryos and newborn mice. ${ }^{39}$

AQP4 is also connected with the $\alpha-\beta$ complex and $\alpha$-DG is linked to laminin and agrin, a proteoglycan present in the basement membrane of cerebral capillaries, involved in BBB integrity. ${ }^{56}$ Moreover, the correct AQP4 and Kir 4.1 clustering on glial membranes required $\alpha$-DG and laminin. ${ }^{15,30,57}$ In glioma cells, agrin deficiency is coupled with redistribution of AQP4 and syntrophins, loss in $\alpha$-DG and absence of OAPs. ${ }^{12,58}$ It is important to note that agrin is also able to induce AQP4 clustering into OAP membranes, ${ }^{15,59}$ suggesting that AQP4 and DG are components of OAPs. ${ }^{60}$

The findings that AQP4 and OAPs are concentrated on the glial endfeet as opposed to the basement membrane, ${ }^{4,7}$ and are reduced in the neurological disorders affecting the $\mathrm{BBB}$ including brain tumors, in which edema and AQP4 redistribution on glioma cell membrane occurred, ${ }^{12,16,17,61}$ suggest a role of basement membrane components in the polarity and functions of the astroglial endfeet.

Alterations of $\alpha$-DG recognizable in muscular dystrophy ${ }^{45}$ seem to affect their binding to laminin and agrin. ${ }^{62,63}$ Moreover, altered $\alpha$-DG glycosylation and AQP4 and Kir 4.1 mislocation, as well as $\beta 1$-syntrophin deficiency in perivascular domains, have been reported in an animal model of 

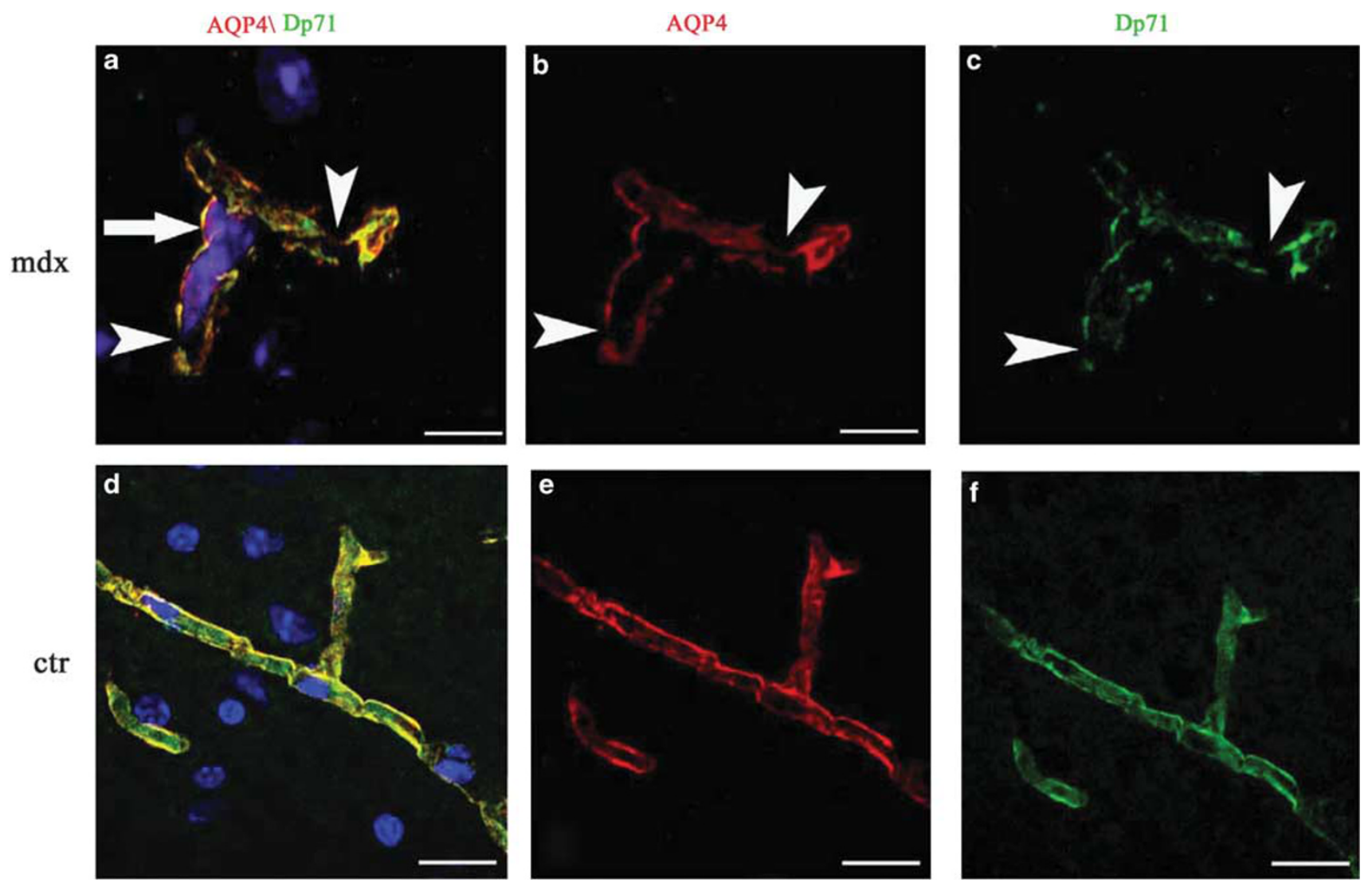

Figure 9 Confocal dual immunofluorescence reaction of AQP4 (red) and dystrophin isoform (Dp71) (green) in $m d x(\mathbf{a}-\mathbf{c})$ and control vessels (d-f). A light orange signal of AQP4 and Dp71 codistribution is present in a discontinuous pattern in the $m d x$ vessel (a, arrow), showing unlabeled areas (a-c arrowhead) alternating with labeled ones, whereas in the control vessel (d-f), a strong and continuous merge fluorescence is evident. Scale bar: $\mathbf{a}-\mathbf{f}, 25 \mu \mathrm{m}$.

Table 3 Quantitation of alterations in perivascular glial endfeet and basement membrane in $m d x$ and control brain

\begin{tabular}{|c|c|c|c|c|c|c|}
\hline & $\begin{array}{l}\text { Number of glial } \\
\text { endfeet } \\
\text { examined }\end{array}$ & $\begin{array}{l}\text { Number of } \\
\text { unswollen glial } \\
\text { endfeet }\end{array}$ & $\begin{array}{l}\text { Number of swollen } \\
\text { glial endfeet }\end{array}$ & $\begin{array}{l}\text { Basement membrane } \\
\text { thickness }\end{array}$ & $\begin{array}{l}\% \text { of abluminal vessels } \\
\text { surface covered by basement } \\
\text { membrane }\end{array}$ & $\begin{array}{c}\% \text { of abluminal vessels } \\
\text { surface covered by glial } \\
\text { endfeet }\end{array}$ \\
\hline Control & 92 & $81 \pm 5^{b}$ & $4 \pm 1$ & $65 \pm 8.8 \mathrm{~nm}$ & $93 \% \pm 14^{b}$ & $89 \% \pm 11^{b}$ \\
\hline
\end{tabular}

${ }^{\mathrm{a}} P<0.0001$ vs control.

${ }^{\mathrm{b}} \mathrm{P}<0.0001$ vs $m d x$.

dystroglycanopathies, supporting the role of a correct link between the extracellular matrix and DAPs in the clustering of the channel proteins. ${ }^{64}$ Accordingly, in this study we have observed that, whereas in control brain, AQP4 colocalized with $\alpha-\beta$-DG, in the $\mathrm{mdx}$ brain, a reduction in both proteins and mRNA expression was observed, and by confocal microscopy we have detected a translocation of $\alpha-\beta$-DG, which was not colocalized with AQP4. Immunogold experiments confirmed these data, showing that $\alpha-\beta$-DG gold particles were attached on the glial membranes facing the vessel basement membrane in the control brain, whereas they are scattered on the glial cytoplasms in the $m d x$ brain.

Although $\alpha-\beta$-DG is downregulated in muscle fibers of DMD and in $m d x$ mice, ${ }^{65,66}$ in $m d x$ brain only $\alpha$-DG is reduced, ${ }^{63}$ suggesting that $\beta$-DG is linked to $\alpha$-DG outside the plasma membrane. Our results, demonstrating a parallel $\alpha-\beta$-DG decrease and molecular rearrangment, together with laminin and agrin deficiency, suggest indeed that the entire DG complex is involved in a correct DAP anchoring on the basement membrane. 


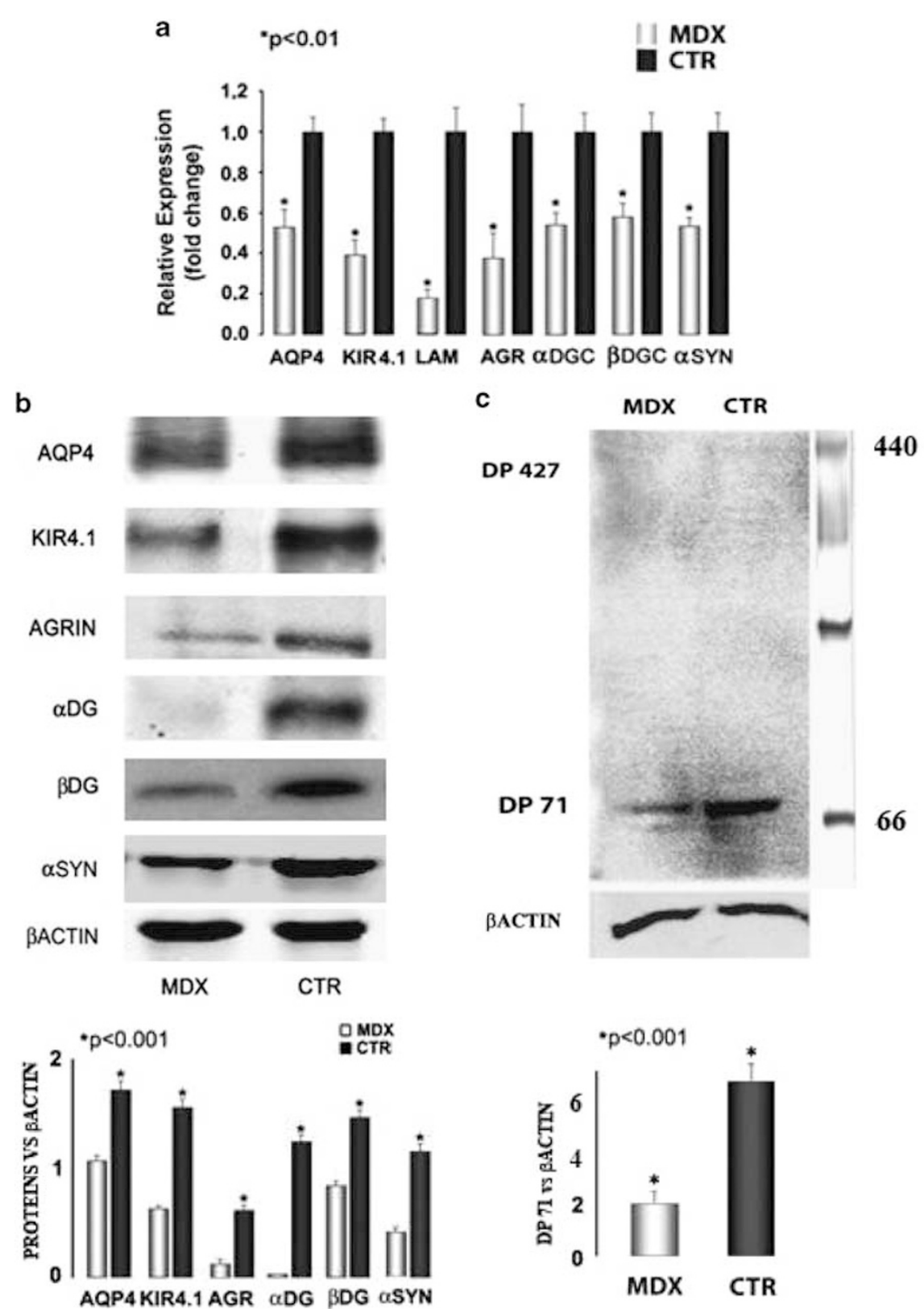

Figure 10 (a) Total RNA $(1 \mu \mathrm{g})$ was reverse transcribed to CDNA and used in real-time PCR to evaluate the messenger expression, using specific primers for murine aquaporin-4, $\alpha$ - $\beta$-dystroglycan, Kir $4.1, \alpha$-syntrophin, laminin and agrin. The $m d x$ mice brains have a higher expression in all the genes screened compared with the controls as shown in the histogram correspondent to their relative fold change. In this experiment, the fold change is normalized to actin. Data are representative of three independent experiments. (b) Western blotting analysis of aquaporin-4, $\alpha$ - $\beta$-dystroglycan, Kir $4.1, \alpha$-syntrophin, laminin and agrin in brain homogenates of $m d x$ and control (ctr) mice. Quantification of the bands revealed a significantly higher level of all the protein in $m d x$ brain with respect to the control. The data are representative of three independent experiments. (c) Western blotting analysis of short dystrophin isoform (Dp71) showing a lower expression in $m d x$ brain with respect to the control. The absence of signal corresponding to 427-kDa molecular weight indicated the specificity of antibody against the 71-kDa dystrophin isoform. The data are representative of three independent experiments.

In this study, we have demonstrated that the perivascular basement membrane of $m d x$ brain appeared thickened or absent and it was deficient in laminin and agrin protein content and expression. It is well known that basement membrane has a key role in BBB development and stabilization $^{7,60,67,68}$ and that laminin and agrin deficiency is associated with BBB alterations. ${ }^{58,69,70}$ It is to be noted that both laminin and agrin bind $\alpha-\beta$-DG complex ${ }^{30}$ and that, in Muller cells, laminin, by inducing a polarized Kir 4-1 expression, is involved in cleaning excess potassium. ${ }^{57}$

Furthermore, it has been demonstrated that, in brain angiogenesis, occurring in both physiological and pathological 

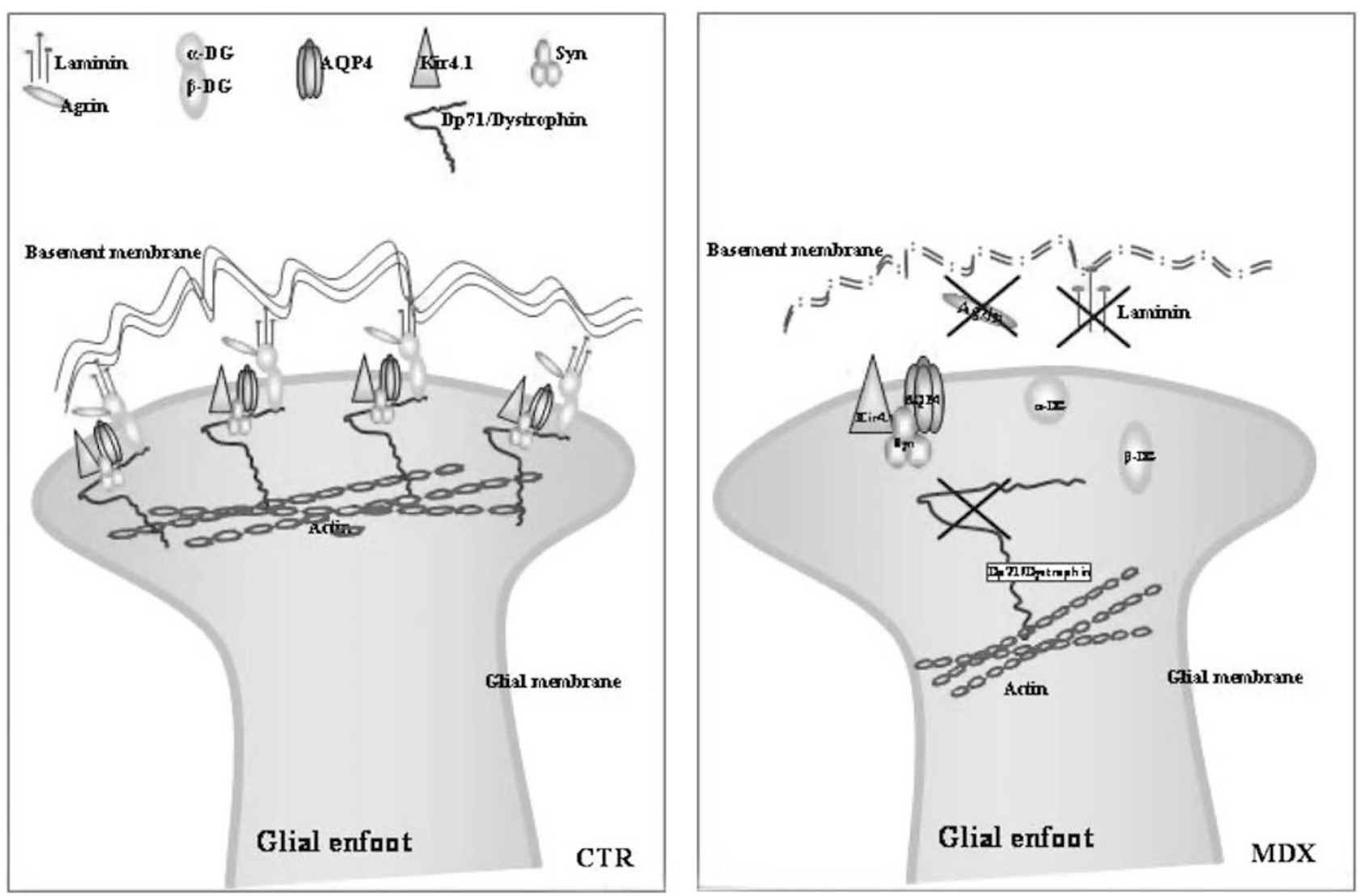

Figure 11 Schematic drawing showing a possible association between DAPs, AQP4, Kir 4.1, syntrophin (Syn), $\alpha-\beta$-DG and dystrophin isoform Dp71 in the perivascular glial membrane of a control (ctr) and $m d x$ mouse.

conditions, basement membrane was degraded by the activity of MMP-2 and MMP-9. ${ }^{71}$

Agrawal et $a l^{71}$ demonstrated that the $\beta$-DG in the astrocytic endfeet membrane, which was selectively cleaved by MMP-2 and -9, was specifically involved in the destruction of the basement membrane and $\mathrm{BBB}$ opening in an animal model of multiple sclerosis.

We have previously reported that in the $m d x$ brain, enhance angiogenesis was associated with an overexpression of MMP-2 and MMP-9 by glial cells. ${ }^{41}$ On this basis, it might occur that, in the $m d x$ brain, active MMPs induce DG cleavage, leading to $\alpha-\beta-\mathrm{DG}$ translocation and basement membrane fragmentation, and, in turn, laminin and agrin deficiency might contribute to AQP4-Kir 4.1 downregulation.

Overall, the results of this study suggest that dystrophin isoform (Dp71) and DAPs could be involved in the morphological and functional polarization of astrocytes in the BBB and that in the mdx brain their deficiency coupled with structural and molecular modifications of basement membrane could be responsible for the BBB alterations occurring in this pathological condition (Figure 11).

It should be clarified whether the basement membrane alterations are primarily responsible for the altered DAPs anchoring to the glial cells or whether the deficiency of dystrophin isoform primarily induces the disassembly of the DAP complex and consequently the basement membrane alterations.

\section{ACKNOWLEDGEMENT}

This study was supported in part by grants from Fondazione Cassa di Risparmio di Puglia, Bari, Italy and from MIUR (PRIN 2007 and local fund), Rome.

\section{DISCLOSURE/CONFLICT OF INTEREST}

The authors declare no conflict of interest.

1. Wolburg $\mathrm{H}$, Lippoldt A. Tight junctions of the blood-brain barrier: development, composition and regulation. Vascul Pharmacol 2002;38:323-337.

2. Abbott NJ, Rönnbäck L, Hansson E. Astrocyte-endothelial interactions at the blood-brain barrier. Nat Rev Neurosci 2006;7:41-53.

3. Zlokovic BV. The blood-brain barrier in health and chronic neurodegenerative disorders. Neuron 2008;57:178-201.

4. Nielsen $S$, Nagelhus EA, Amiry-Moghaddam $M$, et al. Specialized membrane domains for water transport in glial cells: high- resolution immunogold cytochemistry of aquaporin-4 in rat brain. J Neurosci 1997;17:171-180.

5. Verbavatz JM, Ma T, Gobin R, et al. Absence of orthogonal arrays in kidney, brain and muscle from transgenic knockout mice lacking water channel aquaporin-4. J Cell Sci 1997;110:2855-2860. 
6. Rash JE, Yasumura T, Hudson CS, et al. Direct immunogold labeling of aquaporin-4 in square arrays of astrocyte and ependymocyte plasma membranes in rat brain and spinal cord. Proc Natl Acad Sci USA 1998;95:11981-11986.

7. Nico B, Frigeri A, Nicchia GP, et al. Role of aquaporin-4 water channel in the development and integrity of the blood-brain barrier. J Cell Sci 2001;114:1297-1307.

8. Newman EA, Frambach DA, Odette LL. Control of extracellular potassium levels by retinal glial cell $\mathrm{K}+$ siphoning. Science 1984;225:1174-1175.

9. Nagelhus EA, Horio $Y$, Inanobe A, et al. Immunogold evidence suggests that coupling of $\mathrm{K}+$ siphoning and water transport in rat retinal Müller cells is mediated by a coenrichment of Kir4.1 and AQP4 in specific membrane domains. Glia 1999;26:47-54.

10. Connors NC, Kofuji P. Dystrophin Dp71 is critical for the clustered localization of potassium channels in retinal glial cells. J Neurosci 2002;22:4321-4327.

11. Fort PE, Sene A, Pannicke T, et al. Kir4.1 and AQP4 associate with Dp71and utrophin DAPs complexes in specific and defined microdomains of Muller retinal glial cell membrane. Glia 2008;56:597-610.

12. Warth $A$, Mittelbronn $M$, Wolburg $H$. Redistribution of the water channel protein aquaporin- 4 and the $\mathrm{K}+$ channel protein Kir4.1 differs in low- and high-grade human brain tumors. Acta Neuropathol 2005;109:418-426.

13. Amiry-Moghaddam $M$, Williamson $A$, Palomba $M$, et al. Delayed $K+$ clearance associated with aquaporin-4 mislocalization: phenotypic defects in brains of alphasyntrophin- null mice. Proc Natl Acad Sci USA 2003;100:13615-13620.

14. Wolburg H. Orthogonal arrays of intramembranous particles: a review with special reference to astrocytes. J Hirnforsch 1995;36:239-258.

15. Noël G, Tham DK, Moukhles H. Interdependence of laminin-mediated clustering of lipid rafts and the dystrophin complex in astrocytes. J Biol Chem 2009;284:19694-19704.

16. Nico B, Mangieri D, De Luca A, et al. Nerve growth factor and its receptors TrkA and p75 are upregulated in the brain of $\mathrm{mdx}$ dystrophic mouse. Neuroscience 2009;161:1057-1066.

17. Saadoun S, Papadopoulos MC, Davies DC, et al. Aquaporin-4 expression is increased in oedematous human brain tumours. J Neurol Neurosurg Psychiatry 2002;72:262-265.

18. Haenggi T, Fritschy JM. Role of dystrophin and utrophin for assembly and function of the dystrophin glycoprotein complex in non-muscle tissue. Cell Mol Life Sci 2006;63:1614-1631.

19. Blake DJ, Hawkes R, Benson MA, et al. Different dystrophin-like complexes are expressed in neurons and glia. J Cell Biol 1999;147: 645-658.

20. Jancsik V, Hajós $F$. The demonstration of immunoreactive dystrophin and its developmental expression in perivascular astrocytes. Brain Res 1999:831:200-205.

21. Lidov HG, Byers TJ, Watkins SC, et al. Localization of dystrophin to postsynaptic regions of central nervous system cortical neurons. Nature 1990;348:725-728.

22. Lederfein $\mathrm{D}$, Levy $\mathrm{Z}$, Augier $\mathrm{N}$, et al. A 71-kilodalton protein is a major product of the Duchenne muscular dystrophy gene in brain and other nonmuscle tissues. Proc Natl Acad Sci USA 1992;89:5346-5350.

23. Kim TW, Wu K, Xu JL, et al. Detection of dystrophin in the postsynaptic density of rat brain and deficiency in a mouse model of Duchenne muscular dystrophy. Proc Natl Acad Sci USA 1992;89: 11642-11644.

24. Lidov HG, Byers TJ, Kunkel LM. The distribution of dystrophin in the murine central nervous system: an immunocytochemical study. Neuroscience 1993;54:167-187.

25. Lidov HG, Selig S, Kunkel LM. Dp140: a novel 140 kDa CNS transcript from the dystrophin locus. Hum Mol Genet 1995;4:329-335.

26. Blake DJ, Kröger $S$. The neurobiology of Duchenne muscular dystrophy: learning lessons from muscle? Trends Neurosci 2000;23:92-99.

27. Amiry-Moghaddam M, Ottersen OP. The molecular basis of water transport in the brain. Nat Rev Neurosci 2003;4:991-1001.

28. Connors NC, Adams ME, Froehner SC, et al. The potassium channel Kir4.1 associates with the dystrophin-glycoprotein complex via alpha-syntrophin in glia. J Biol Chem 2004;279: 28387-28392.

29. Leonoudakis D, Conti LR, Anderson S, et al. Protein trafficking and anchoring complexes revealed by proteomic analysis of inward rectifier potassium channel (Kir2.x)-associated proteins. J Biol Chem 2004;279:22331-22346.

30. Guadagno E, Moukhles H. Laminin-induced aggregation of the inwardly rectifying potassium channel, Kir4.1, and the waterpermeable channel, AQP4, via a dystroglycan-containing complex in astrocytes. Glia 2004;47:138-149.

31. Neely JD, Amiry-Moghaddam M, Ottersen OP, et al. Syntrophindependent expression and localization of Aquaporin-4 water channel protein. Proc Natl Acad Sci USA 2001;98:14108-14113.

32. Ozawa E, Yoshida M, Suzuky A, et al. Dystrophin-associated proteins in muscular dystrophy. Human Mol Genet 1995;4:1711-1716.

33. Bulfiled G, Siller WG, Wight PA, et al. X-chromosome-linked muscular dystrophy $(\mathrm{mdx})$ in the mouse. Proc Natl Acad Sci USA 1984;81:1189-1192.

34. Emery AEH. Heterogeneity in Duchenne muscular dystrophy. Am J Med Genet 1987;26:235-236.

35. Koening $M$, Monaco AP, Kunkel LM. The complete sequence of dystrophin predicts a rod shaped cytoskeletal protein. Cell 1988;53:219-228.

36. Muntoni F, Mateddu A, Serra A. Passive avoidance behaviour deficit in mdx mouse. Neuromusc Disord 1991;1:121-123.

37. Mehler MF. Brain dystrophin, neurogenetics and mental retardation. Dev Brain Res 2000;32:277-307.

38. Nico B, Frigeri A, Nicchia GP, et al. Severe alterations of endothelial and glial cells in the blood-brain barrier of dystrophic mice. Glia 2003;42:235-251.

39. Nico B, Nicchia GP, Frigeri A, et al. Altered blood-brain barrier development in dystrophic $\mathrm{mdx}$ mice. Neuroscience 2004;125: 921-935.

40. Nico B, Corsi P, Vacca A, et al. Vascular endothelial growth factor and vascular endothelial growth factor receptor-2 expression in $\mathrm{mdx}$ mouse brain. Brain Res 2002;953:12-16.

41. Nico B, Corsi $P$, Ria R, et al. Increased matrix-metalloproteinase-2 and matrix-metalloproteinase-9 expression in the brain of dystrophic $\mathrm{mdx}$ mouse. Neuroscience 2006;140:835-848.

42. Nico B, Mangieri D, Crivellato $E$, et al. HIF activation and VEGF overexpression are coupled with ZO-1 up-phosphorylation in the brain of dystrophic mdx mouse. Brain Pathol 2007;17:399-406.

43. Pfaffl MW. A new mathematical model for relative quantification in real-time RT-PCR. Nucleic Acids Res 2001;29:e45.

44. Inoue M, Wakayama Y, Liu JW, et al. Ultrastructural localization of aquaporin 4 and alpha1-syntrophin in the vascular feet of brain astrocytes. Tohoku J Exp Med 2002;197:87-93.

45. Michele DE, Campbell KP. Dystrophin-glycoprotein complex: posttranslational processing and dystroglycan function. J Biol Chem 2003;278:15457-15460.

46. Moore SA, Saito F, Chen J, et al. Deletion of brain dystroglycan recapitulates aspects of congenital muscular dystrophy. Nature 2002;418:422-425

47. Aleman V, Osorio B, Chavez O, et al. Subcellular localization of Dp71 dystrophin isoforms in cultured hippocampal neurons and forebrain astrocytes. Histochem Cell Biol 2001;115:243-254.

48. Connors NC, Kofuji P. Potassium channel Kir4.1 macromolecular complex in retinal glial cells. Glia 2006;53:124-131.

49. Nicchia GP, Nico B, Camassa LM, et al. The role of aquaporin-4 in the blood-brain barrier development and integrity: studies in animal and cell culture models. Neuroscience 2004;129:935-945.

50. Nagelhus EA, Mathiisen TM, Ottersen OP. Aquaporin-4 in the central nervous system: cellular and subcellular distribution and coexpression with KIR4.1. Neuroscience 2004;129:905-913.

51. Dalloz C, Sarig R, Fort $P$, et al. Targeted inactivation of dystrophin gene product Dp71: phenotypic impact in mouse retina. Hum Mol Genet 2003;12:1543-1554.

52. Adams ME, Mueller HA, Froehner SC. In vivo requirement of the alphasyntrophin PDZ domain for the sarcolemmal localization of $\mathrm{nNOS}$ and aquaporin-4. J Cell Biol 2001;155:113-122.

53. Yokota T, Miyagoe $Y$, Hosaka $Y$, et al. Aquaporin-4 is absent at the sarcolemma and at perivascular astrocyte endfeet in a1-syntrophin knockout mice. Proc Japan Acad 2000;76:22-27.

54. Saadoun S, Papadopoulos MC, Krishna S. Water transport becomes uncoupled from $\mathrm{K}+$ siphoning in brain contusion, bacterial meningitis, and brain tumours: immunohistochemical case review. J Clin Pathol 2003;56:972-975. 
55. Puwarawuttipanit W, Bragg AD, Frydenlund DS, et al. Differential effect of alpha-syntrophin knockout on aquaporin-4 and Kir4.1 expression in retinal macroglial cells in mice. Neuroscience 2006;137:165-175.

56. Smith MA, Hilgenberg LG. Agrin in the CNS: a protein in search of a function? Neuroreport 2002;13:1485-1495.

57. Noël G, Belda M, Guadagno E, et al. Dystroglycan and Kir4.1 coclustering in retinal Müller glia is regulated by laminin-1 and requires the PDZligand domain of Kir4.1. J Neurochem 2005;94:691-702.

58. Warth A, Kröger S, Wolburg H. Redistribution of aquaporin-4 in human glioblastoma correlates with loss of agrin immunoreactivity from brain capillary basal laminae. Acta Neuropathol 2004;107:311-318.

59. Gee $\mathrm{SH}$, Montanaro $\mathrm{F}$, Lindenbaum $\mathrm{MH}$, et al. Dystroglycan-alpha, a dystrophin-associated glycoprotein, is a functional agrin receptor. Cell 1994;77:675-686.

60. Wolburg H. The endothelial frontier. In: Dermietzel R, Spray DC, Nedergaard M (eds). Blood-Brain Interfaces: From Ontogeny to Artificial Barriers. Wiley-VCH: Weinheim, 2006, pp 77-107.

61. Rohlmann A, Gocht A, Wolburg H. Reactive astrocytes in myelindeficient rat optic nerve reveal an altered distribution of orthogonal arrays of particles (OAP). Glia 1992;5:259-268.

62. Grewal PK, Hewitt JE. Glycosylation defects: a new mechanism for muscular dystrophy? Hum Mol Genet 2003;2:R259-R264.

63. Culligan K, Glover L, Dowling P, et al. Brain dystrophin-glycoprotein complex: persistent expression of beta-dystroglycan, impaired oligomerization of Dp71 and up-regulation of utrophins in animal models of muscular dystrophy. BMC Cell Biol 2001;2:2.
64. Rurak J, Noel G, Lui L, et al. Distribution of potassium ion and water permeable channels at perivascular glia in brain and retina of the Large(myd) mouse. J Neurochem 2007;103: 1940-1953.

65. Uchino $M$, Hara $A$, Mizuno $Y$, et al. Distribution of dystrophin and dystrophin-associated protein 43DAG (beta-dystroglycan) in the central nervous system of normal controls and patients with Duchenne muscular dystrophy. Intern Med 1996;35: 189-194.

66. Ohlendieck K, Campbell KP. Dystrophin-associated proteins are greatly reduced in skeletal muscle from $\mathrm{mdx}$ mice. J Cell Biol 1991;115:1685-1694.

67. Risau W. Induction of blood-brain barrier endothelial cell differentiation. Ann NY Acad Sci USA 1992;633:405-419.

68. Wolburg H, Noell S, Mack A, et al. Agrin accumulates in the brain microvascular basal lamina during development of the blood-brain barrier. Dev Dyn 1997;208:62-74.

69. Rascher G, Fischmann A, Kröger $S$, et al. Extracellular matrix and the blood-brain barrier in glioblastoma multiforme: spatial segregation of tenascin and agrin. Acta Neuropathol 2002;104:85-91.

70. Rosenberg GA. Matrix metalloproteinase in neuroinflammation. Glia 2002;39:279-291.

71. Agrawal S, Anderson P, Durbeej M, et al. Dystroglycan is selectively cleaved at the parenchymal basement membrane at sites of leukocyte extravasation in experimental autoimmune encephalomyelitis. J Exp Med 2006;203:1007-1019. 